\title{
The Economic Impact of AIDS Treatment: Labor Supply in Western Kenya
}

\author{
Harsha Thirumurthy, Joshua Graff Zivin, and Markus Goldstein \\ University of North Carolina at Chapel Hill, Columbia University, The World Bank
}

\begin{abstract}
Using longitudinal survey data collected in collaboration with a treatment program, this paper estimates the economic impacts of antiretroviral treatment. The responses in two outcomes are studied: (1) labor supply of treated adult AIDS patients; and (2) labor supply of individuals in patients' households. Within six months after treatment initiation, there is a 20 percent increase in the likelihood of the patient participating in the labor force and a 35 percent increase in weekly hours worked. Young boys in treated patients' households work significantly less after treatment initiation, while girls and adult household members do not change their labor supply.
\end{abstract}

\section{Introduction}

Sub-Saharan Africa is home to 25 million of the nearly 40 million people living with HIV/ AIDS worldwide (UNAIDS 2006). In the next decade, AIDS-related mortality in Africa has the potential to generate growing numbers of orphans (already 12 million), while also shortening life expectancy to below 40 years in a number of countries. Following increases in donor support and substantial reductions in the prices of medicines, antiretroviral (ARV) therapy has recently become an important part of the policy response to combat AIDS. ${ }^{1}$ As of December 2005, roughly eight hundred thousand HIV-positive individuals were receiving ARV therapy in sub-Saharan Africa (WHO 2006). Since this represents only 17 percent of the number of people needing treatment, scaling-up of treatment programs poses a major challenge in many countries. ${ }^{2}$ At the same time, however, some have questioned the investment in ARV therapy since most low-income countries have limited resources and many competing needs (Marseille, Hofmann, and Kahn 2002; Kremer 2002; Canning 2006).

Numerous studies have shown that ARV therapy dramatically reduces morbidity and mortality among HIV-infected individuals, in both industrialized countries (Hammer et al. 1997, Hogg et al. 1998; Palella et al. 1998) and developing countries (Laurent et al. 2002; Marins et al. 2003; Koenig, Leandre, and Farmer 2004; Coetzee et al. 2004; WoolsKaloustian et al. 2006). These health benefits have the potential to significantly improve economic well-being, as suggested by a growing literature that shows linkages between health and income in developing countries. ${ }^{3}$ While this literature examines the economic impacts of several dimensions of health such as nutritional status and morbidity, it provides little guidance when it comes to a highly debilitating and chronic disease like HIV/AIDS. One exception is the recent study by Fox et al. (2004), who analyze retrospective data from a Kenyan tea estate and find significant declines in the labor productivity of HIV-positive

\footnotetext{
${ }^{1}$ For example, in 2003 the World Health Organization (WHO) launched the prominent " 3 by 5 " campaign, with the goal of treating three million people by 2005 (WHO 2003).

${ }^{2}$ As explained below, not all HIV-positive individuals are currently in need of ARV therapy.

${ }^{3}$ See Strauss and Thomas (1998), Ruger, Jamison, and Bloom (2001), and Thomas and Frankenberg (2002) for reviews and discussions of the micro-economic literature on linkages between health and income.
} 
workers prior to their death or medical retirement. However, the extent to which treatment can reverse such declines in labor productivity remains to be determined. Little is known about the impact of this important intervention on a broad range of other socio-economic outcomes as well, both at the individual and household level.

In this paper, we use survey data from Kenya to present the first estimates of how quickly and to what degree ARV therapy affects the labor supply of treated patients and their household members. These estimates are a preliminary step in understanding the socioeconomic impacts of ARV therapy, which in turn is critical for properly evaluating treatment programs and efficiently allocating resources. For example, if ARV therapy for adult AIDS patients increases the likelihood that their children attend school, then such impacts belong in any cost-benefit analysis. Of course, an assessment of the impacts of treatment also provides valuable information about the impacts of the disease absent treatment and as such our results could be viewed as a lower bound for the labor supply declines due to HIV/AIDS as well. Estimates of these impacts can also contribute to the growing literature on the long-term micro- and macroeconomic consequences of AIDS (e.g. Bell, Devarajan, and Gersbach (2003) and Young (2005)).

Labor is the central productive asset of the poor in most developing countries. Indeed, labor supply and related outcomes like income have been the focus of many studies that examine the impacts of nutrition, morbidity, and AIDS-related mortality. ${ }^{4}$ Because it is an important outcome, changes in the labor supply of adult AIDS patients can also generate intrahousehold spillover effects on time allocation patterns and influence other measures of household welfare.

Our analysis is based on data from a household survey we conducted in collaboration with a rural treatment program in western Kenya. Over the course of one year, longitudinal socioeconomic data were collected from AIDS patients who receive free treatment. These data have been linked to longitudinal medical data containing clinical and laboratory measures of the patients' health status. The presence of individuals whose HIV status is known, the ARV treatment program, and the linked medical data combine to offer us a unique opportunity to measure the effects of treatment.

To identify the response to treatment, we examine changes over time in the labor supply of treated patients and their household members. Since ARV treatment eligibility is defined by biological markers that are not easily influenced by the behavior of patients with late-stage HIV disease, the provision of treatment at our study clinic and the resulting changes in health are exogenous. ${ }^{5}$ Using data collected simultaneously from a large random sample of non-patient households, we control for time-varying factors (such as seasonality) that could bias the estimates. The analysis is strengthened by variation in the length of time that patients had been exposed to treatment prior to the start of our survey. As we show with the linked medical data, health has a non-linear temporal response to treatment-it improves dramatically in the first months of treatment but more gradually thereafter. We exploit this nonlinearity to test for heterogeneous treatment responses in the labor supply of patients.

We find that the provision of ARV therapy leads to a large and significant increase in the labor supply of AIDS patients. This increase occurs very soon after the initiation of ARV therapy: within six months, there is a 20 percent increase in the likelihood of participating in the labor force and a 35 percent increase in hours worked - an impressive 7.9 hours - during

\footnotetext{
${ }^{4}$ Yamano and Jayne (2004) examine the impacts of working-age adult mortality on a range of household outcomes including crop and non-farm income. Beegle (2005) examines the impacts of adult mortality on the labor supply of household members.

${ }^{5}$ Patients at the clinic where this study was conducted were not charged for laboratory tests and medicines, and treatment was provided to all patients who required it on clinical grounds.
} 
the past week. Since AIDS patients left untreated will experience continued declines in health and possibly death within six months, our estimated labor supply responses are therefore underestimates of the impact of treatment on the treated. As such, we also calculate an upper bound of the impact of treatment on the treated by assuming that patients would be too sick to work (or even dead) without treatment. Clinical evidence on the evolution of untreated HIV disease suggests that this is a reasonable assumption, and that the upper bound estimate is close to the 'true' impact of treatment on the treated. This upper bound is very large: over a period of six months, labor force participation for those initiating therapy at the beginning of our survey increases by 85 percentage points and hours worked increases by 26 hours per week relative to what would have happened if AIDS had progressed untreated.

Given this effect on patients' labor supply, treatment can also have spillover benefits within the household. However, an analysis of how ARV therapy influences the labor supply of treated patients' household members is complicated, as the effects are theoretically ambiguous. On the one hand, the increase in a patient's labor supply has an income effect that allows other household members to work less. On the other hand, the improvement in the patient's health reduces the care-taking and housework burden on family members, thereby having a time endowment effect that allows for more work and leisure. We find that the labor supply of younger boys in patients' households declines after the initiation of ARV therapy, suggesting that the income effect from the treated patients' increased labor supply dominates. In multiple-patient households, both younger and older boys, as well as other adults in the household, work less after patients receive treatment. This suggests that intrahousehold decisions about time allocation are influenced by the provision of treatment, and that the welfare of some household members beyond the patient may increase considerably as a result. The effects on the labor supply of younger children are particularly important since they suggest, among other things, potential schooling impacts from treatment, and the returns to primary school education are especially large in developing countries.

This paper is organized as follows: in Section II, we provide a brief overview of the key stages of HIV infection and the role of ARV therapy in treating infected individuals. We then discuss our survey data in Section III. Section IV uses medical data from the HIV clinic where this study was conducted to show that measurable dimensions of patient health improve after initiation of treatment. We discuss our strategy for estimating the response in treated patients' labor supply in Section V and present the results in Section VI. In Section VII, we examine the labor supply of children and adults living with ARV recipients. Section VIII concludes and discusses the policy implications of this research.

\section{Background on HIV/AIDS and Antiretroviral Therapy}

The human immunodeficiency virus (HIV) affects the health of individuals and eventually causes acquired immune deficiency syndrome (AIDS) because it destroys white blood cells that are essential to the immune system. In sub-Saharan Africa, most HIV transmission among adults occurs through sexual intercourse between men and women (UNAIDS 2006). Soon after transmission, infected individuals enter a clinical latent period of many years during which health status declines gradually and few symptoms are experienced. Median time from seroconversion to AIDS in east Africa is estimated to be 9.4 years (Morgan et al. 2002). ${ }^{6}$ During this latency period, most HIV-positive individuals are unaware of their status and physically capable of performing all normal activities.

Over time, almost all HIV-infected individuals will experience a weakening of the immune system and progress to developing AIDS. This later stage is very often associated with 
substantial weight loss (wasting) and opportunistic infections such as P. carinii pneumonia, Kaposi's sarcoma, and tuberculosis. In resource-poor settings, absent treatment with ARV therapy, death usually occurs rapidly after progression to AIDS. One study in Uganda reports a median survival time of 9.2 months (Morgan et al. 2002) and another study in Brazil reports a median survival time of 5.1 months (Chequer et al. 1992). These estimates are not very different from those found for untreated populations in industrialized countries, where the estimated survival times following clinical diagnosis of AIDS are about one year (Lemp et al. 1990; Lee et al. 2001).

Highly active antiretroviral therapy ${ }^{7}$ has been proven to reduce the likelihood of opportunistic infections and prolong the life of HIV-infected individuals. After several months of treatment, patients are generally asymptomatic and have improved functional capacity. As we discuss in Section IV, individuals are considered eligible for ARV therapy after they progress to AIDS. Numerous studies in various countries and patient populations have reported positive results. ${ }^{8}$ In Haiti, patients had weight gain and improved functional capacity within one year after the initiation of ARVs (Koenig, Leandre, and Farmer 2004). In Brazil, median survival time after developing AIDS rose to 58 months with ARV therapy (Marins et al. 2003). Section IV documents similar health impacts for patients in our sample.

The price of ARV therapy in developing countries is an important issue in discussions about treatment provision. First-line ARV regimens used to cost more than $\$ 10,000$ per patient per year. However, since 2000 widespread generic production of medicines has reduced these prices significantly, to as low as $\$ 140$ (negotiated by the Clinton Foundation for treatment in selected countries) in 2004 (Gutierrez et al. 2004; Campaign for Access to Essential Medicines 2005). Further declines may be possible with greater generic competition and bulk purchasing agreements. Expenditures on lab tests and HIV clinic operations can also be sizable, with the sum of these non-drug costs dependent on the treatment setting.

\section{Sampling Strategy and Survey Data}

The socio-economic data used in this paper come from a household survey we conducted in Kosirai Division, a rural region near the town of Eldoret, in western Kenya. ${ }^{9}$ The Division has an area of 76 square miles and a population of 35,383 individuals living in 6,643 households (Central Bureau of Statistics 1999). Households are scattered across more than 100 villages where crop farming and animal husbandry are the primary economic activities and maize is the major crop.

The largest health care provider in the survey area is the Mosoriot Rural Health Training Center, a government health center that offers primary care services. The health center also contains a clinic that provides free medical care (including all relevant medical tests and ARV therapy) to HIV-positive patients. This rural HIV clinic (one of the first in sub-Saharan Africa) was opened in November 2001 by the Academic Model for the Prevention and Treatment of HIV/AIDS (AMPATH). ${ }^{10}$ Following increased funding since late-2003, the

\footnotetext{
${ }^{6}$ Conversion to HIV-positive serology normally occurs 4-10 weeks after transmission. The duration of the clinical latent period has been found to vary considerably, depending upon the mode of transmission and age at transmission (Collaborative Group on AIDS Incubation and HIV Survival including the CASCADE EU Concerted Action 2000). In developing countries, limited access to health care and greater burden of other infectious diseases may expedite the progression of HIV.

7In this paper, we use the terms "ARV therapy" and "ARV treatment" to refer to highly active antiretroviral therapy (HAART), which was introduced in 1996. HAART always consists of three antiretroviral medications, with a common first-line regimen of nevirapine, stavudine, and lamivudine. Generic medications that combine three medications in one pill (such as Triomune) have recently become available.

${ }^{8}$ Since placebo-controlled randomized trials of ARV therapy are ethically infeasible, these studies are either observational cohort studies or randomized trials that compare regimens composed of different antiretroviral medications.

${ }^{9}$ Kenya has an estimated 1.3 million HIV-infected individuals and an adult prevalence rate of 6.1 percent (UNAIDS 2006).
} 
Mosoriot HIV clinic has experienced rapid growth: the number of patients has risen from about 150 in early-2003 to 2,149 in September 2005 (communication with AMPATH), with many patients coming from outside Kosirai Division. During this period, adequate funding has been available to provide free ARV therapy to all patients sick enough (according to WHO treatment guidelines that are discussed in the next section) to require it. ${ }^{11}$

We implemented two rounds of a comprehensive socio-economic survey between March 2004 and February 2005, with an interval of roughly six months between rounds. ${ }^{12}$ The survey sample contains two different groups of households. The first group comprises 503 households chosen randomly from a census of all households in Kosirai Division without an AMPATH patient (random sample households). ${ }^{13}$ The second group comprises 200 households that were chosen at the clinic and contained at least one adult HIV-positive AMPATH patient who began receiving ARV therapy (ARV households) prior to round 2. The ARV sample is part of a larger sample of 260 households containing at least one HIVpositive AMPATH patient (at various stages of HIV disease), all of whom were recruited at the Mosoriot HIV clinic. ${ }^{14},{ }^{15}$ All non-pregnant AMPATH patients who enrolled in the Mosoriot HIV clinic before April 2004 and resided in Kosirai Division were considered eligible for our survey since it would be possible for survey staff to visit these households at home. To obtain a larger sample size, we also conducted in-clinic interviews with a random sample of non-pregnant AMPATH patients who entered the clinic before April but resided outside Kosirai Division and too far away from the clinic to be visited at home. Pregnant women were excluded from the sample because treatment was typically given to these women for the prevention of mother-to-child transmission of HIV, not because the women had become sick enough to require ARV therapy.

Upon completion of the survey, we used the AMPATH Medical Records System (AMRS) which contains clinical and treatment-related information on all patients- to establish which of the HIV-positive AMPATH patients in our sample were receiving ARV therapy. It was established that out of the 260 households with AMPATH patients, there are 217 HIVpositive adults (from 200 households) who began receiving ARV therapy at the Mosoriot HIV clinic prior to the round 2 interview (we report the distribution of treatment start dates in Section IV). ${ }^{16}$ Attrition of entire households between rounds due to refusal or relocation is minimal in the random sample (seven out of 503 households), and attrition of individuals

\footnotetext{
${ }^{10}$ AMPATH is a collaboration between the Indiana University School of Medicine and the Moi University Faculty of Health Sciences (Kenya). Descriptions of AMPATH's work in western Kenya can be found in Mamlin et al. (2004), Cohen et al. (2004), and Einterz et al. (2007).

11 As of November 2005, ARV therapy was being provided to an estimated 55,000 out of 273,000 Kenyans needing treatment (WHO 2006). About 17 percent of the Kenyans receiving ARV therapy are patients at one of AMPATH's urban and rural clinics (based on AMPATH and Kenya statistics from June 2005).

${ }^{12}$ Round 1 was between March and August 2004. Round 2 was between September 2004 and February 2005. The last month in each round contained the fewest interviews since they were mostly spent interviewing the respondents who were not found earlier in the round. In the remaining months, the number of interviews was fairly uniform, with June and December somewhat less intensive (the latter due to holidays at the end of the month).

${ }_{13}$ In the random sample, the HIV status of respondents is usually unknown, unless the respondent gives a self-report of having gone for an HIV test and testing HIV-positive or HIV-negative.

${ }^{14}$ We include in this sample two adults (and their household members) who were originally part of the random sample but enrolled in the AMPATH clinic and began receiving ARV therapy between rounds. As we discuss below, several other patients in the ARV sample also initiated ARV therapy between rounds.

${ }^{15}$ The analysis in this paper excludes the 60 households with HIV-positive AMPATH patients who were in the early stages of HIV disease and were not yet sick enough to require ARV therapy (according to WHO treatment guidelines). We exclude this group from our analysis in this paper because these untreated HIV-positive patients would not have experienced significant health changes during the survey period. The small sample size of these HIV households also limits our ability to use them as a control group in the data analysis. All analysis in the paper is thus restricted to the 200 households with ARV recipients and households from the random sample.

${ }^{16}$ HIV-positive children of adult patients were not interviewed. Included among the 217 adults are household members who were reported by the respondent to be HIV-positive ARV recipients and for whom an AMPATH identification number was found in the AMRS.
} 
due to mortality is also negligible (seven out of 3,009 individuals). We discuss attrition of individuals for reasons such as marriage and employment in the next section. In the ARV sample, a total of 22 patients attrite from the sample between rounds (ten due to mortality, seven due to loss to follow-up ${ }^{17}$, and five due to relocation). In the analysis below, we attempt to correct for bias that may be introduced by this attrition. Furthermore, information on the key labor supply measures used as outcome variables is not available for four patients in round two (because they were away from the household for an extended period). This leaves a total sample of 191 adult ARV recipients who appear in both survey rounds.

The survey included questions about demographic characteristics, health, agriculture, income and employment. In the household visits, teams of male and female enumerators interviewed the household head and spouse as well as a youth in the household. For in-clinic interviews, all information was obtained from the AMPATH patient. In total, 81 percent of all survey households were visited at home. Height and weight measurements were made for children under the age of five years. Relevant outcomes such as asset sales and purchases, child anthropometrics, school enrollment and attendance, income, employment, and food consumption were recorded in each round to obtain longitudinal data.

Table 1 provides an overview of the main characteristics of households in the random sample and ARV sample during round 1. On average, households in the survey area have 6.04 members. ARV households tend to be significantly smaller, with 5.52 members on average. There are also significant differences in the sex and marital status of household heads and the orphan status of children: ARV households are more likely to be headed by a woman who has lost her husband, whereas random sample households are generally headed by a married man. ARV households also own significantly less land and livestock, which is one of several indications from the survey that they are worse off than other households in the community. ${ }^{18}$

\section{ARV Therapy and Patient Health}

The AMPATH Medical Record System (AMRS) contains longitudinal information on the health status of patients at AMPATH's eight HIV clinics in western Kenya. Before estimating how labor supply responds to ARV therapy, we discuss evidence from the AMRS on the health response to treatment.

Since HIV enters and destroys T cells with the protein CD4 on their surface, the CD4+ T cell count is an important indicator of disease progression among HIV-infected individuals. 19 HIV-infected individuals are considered to have developed AIDS when they have one of several opportunistic infections or a CD4 count below $200 / \mathrm{mm}^{3}$. It is at this stage when functional capacity deteriorates and, according to WHO guidelines (WHO 2002), patients should be initiated on ARV therapy. 20

The CD4 count of AMPATH patients is monitored at intervals of roughly six months. ${ }^{21}$ The AMRS also contains more frequent measures of the body mass index (weight/height ${ }^{2}, \mathrm{BMI}$ ), a well-known indicator of short-term health for patients with AIDS (WHO 1995). WoolsKaloustian et al. (2006) have recently analyzed longitudinal data for all non-pregnant adult

\footnotetext{
${ }^{17}$ Loss-to-follow is the term used for patients who did not attend the clinic for several appointments and whose mortality status cannot be established.

${ }^{18}$ For further details on the household survey and the first round data, see Goldstein et al. (2005).

${ }^{19}$ Most uninfected individuals have a CD4+ T cell count of 800 to 1000 per $\mathrm{mm}^{3}$ of blood.

${ }^{20}$ The WHO guidelines have been followed by many treatment programs in developing countries, including AMPATH. See Grubb, Perriens, and Schwartlander (2003) and Mamlin et al. (2004).

${ }^{21}$ The CD4 count was obtained less frequently and at unspecified intervals prior to 2004, when funding was more limited. It is important to note that CD4 counts during this period were conducted free-of-charge.
} 
patients treated with ARV therapy at AMPATH's HIV clinics and found significant increases in the CD4 count and weight following the initiation of treatment. Since the exact timing of this health response among patients in our sample will be useful for motivating our strategy for estimating and interpreting the labor supply response to treatment, we focus here on the AMRS data from patients in our sample.

Figure 1, which shows the mean CD4 count in intervals of ten weeks before and after initiation of treatment (baseline), reveals a pronounced temporal pattern in health status improvements experienced by patients at the Mosoriot HIV clinic. ${ }^{22}$ The response of CD4 count is highly non-linear: at 10-20 weeks, the median CD4 count has risen to levels at which patients are generally asymptomatic. Subsequent changes are smaller and less consistent. ${ }^{23}$ A similar non-linear relationship is found for the BMI (not shown). As will be shown in the next section, this health response pattern has important implications for our identification strategy. The extremely low CD4 counts of patients at the time that treatment is initiated are also noteworthy, as it is suggestive of extremely low life expectancies absent treatment. We discuss the implications of this in subsequent sections.

Since patients do not have a CD4 count in every cell of Figure 1, the cross-sectional relationship shown may differ from the average experience of individual patients. Thus, restricting the analysis to all available post-treatment measures of CD4 count or BMI for the adult ARV recipients in our survey, we estimate the following equation using patient fixed effects:

$$
H_{i t}=\alpha_{i}+\beta_{1} A R V_{i, t-3}+\beta_{2} A R V_{i, t-6}+\beta_{3} A R V_{i, t-9}+\beta_{4} A R V_{i, t-12}+\beta_{5} A R V_{i, t-15}+\beta_{6} A R V_{i, t-18}+\varepsilon_{i t} .
$$

$\alpha_{i}$ is a patient fixed effect, $H_{i t}$ is a measure of patient $i$ 's health status (CD4 count or BMI) during the appointment at time $t$, and $A R V_{i, t-\tau}$ indicates whether or not patient $i$ was receiving ARV therapy $\tau$ months prior to the appointment when health status is measured. 24,25 The omitted time period is the span of three months after initiation of treatment. Table 2 reports results from estimating equation 1 with CD4 and BMI as the dependent variables (columns 1 and 2, respectively). The increase in CD4 count during the first three to six months of ARV therapy is substantial $\left(127 / \mathrm{mm}^{3}\right)$ and statistically significant. After six months of treatment, marginal increases are smaller. For BMI, which is measured more frequently, we estimate a more continuous version of equation 1 with additional time intervals. Here again, the largest increase occurs soon after initiation of treatment, but there are also significant increases in subsequent months.

\footnotetext{
${ }^{22}$ Due to the low frequency at which CD4 count is measured, we chose a group size that is large enough to produce a relatively smooth curve. When mean CD4 counts are calculated for intervals of less than ten weeks, the figure looks similar. Likewise, a similar pattern is evident when median CD4 counts are calculated in each time interval.

${ }^{23}$ These figures do not correct for mortality bias, which will lead to an overestimate of trends in CD4 count and BMI. Since mortality rates are low in the period immediately following treatment, the short-term trends should be relatively accurate. But mortality is more of a concern for long-term trends. Since patients who die are generally those who presented with advanced disease and very low baseline CD4 counts, the long-term trends displayed here will be more applicable to patients who begin treatment before becoming 24 vick.

${ }^{24}$ Since there are very few patients with multiple measurements of CD4 counts during the pre-treatment period, it is not possible to estimate the trajectory of CD4 count in this period with patient fixed effects. In cross-sectional regressions of CD4 count on weeks before initiation of ARV therapy, however, there is a significant overall negative trend in CD4 count prior to initiation (as shown in Figure 1).

25 Following Wools-Kaloustian et al. (2006) and other studies, if a CD4 count is not available at the time ARV therapy is initiated, the baseline CD4 count is taken to be nearest available CD4 count in the three months before or 15 days after the time of initiation.
} 
Finally, for the 191 adult ARV recipients in our sample who appear in both survey rounds, Table 3 reports the number of days that they had been receiving ARV therapy relative to the round 1 interview date. While the average number of days between round 1 and the treatment initiation date is 172 , we find substantial variation here: 19 percent had not yet initiated ARVs at the time of the round 1 interview, and 26 percent had been on ARVs for fewer than 100 days. Figure 2 shows the density of days on treatment as of the round 1 interview and further illustrates the variation within the sample of 191 ARV recipients. Table 3 also summarizes the available data on CD4 counts and BMI at time of treatment initiation, the round 1 interview, and the round 2 interview. The non-linear temporal response of health status to ARV therapy (Figure 1) and the variation in treatment duration as of round 1 (Table 2) illustrates that treated patients in our sample experienced varying amounts of health improvement between the survey rounds. In the next section, we exploit this variation to test for heterogeneous treatment responses in labor supply.

\section{Estimation Strategy for Patients' Labor Supply Response}

We primarily study two outcomes that measure an individual's labor supply: an indicator of participation in any economic activities during the past week and the total number of hours worked in the past week. For all household members older than eight years, the survey recorded this information in each round for three types of activities: wage and salaried jobs, farming on the household's owned or rented land, and non-farm self-employed work. Our measure of market labor supply is defined as the total hours devoted to all of these activities. Information on labor supply of household members was typically provided by the household head, except in the case of clinic interviews, during which the patient provided all information about the household. ${ }^{26}$

The first indication that ARV therapy influences labor supply is provided by Figures 3 and 4, which combine data from the two survey rounds (for the ARV sample only) and plots the relationship between adult ARV recipients' labor supply outcomes and time on treatment. The temporal pattern of labor force participation rates (Figure 3) and weekly hours worked (Figure 4) closely resembles the non-linear response of medical outcomes. In this section, we discuss the main estimation strategies used to test the hypothesis that ARV therapy results in increased labor supply. Results from employing these strategies are presented in the next section.

The motivation for our empirical work comes from the following labor supply function, which is drawn from Strauss and Thomas (1998) and can be used to describe the relationship between health and labor supply:

$$
L=L\left(H, p_{c}, w\left(H, X, \alpha, e_{w}\right), X, \xi\right) .
$$

Labor supply $(L)$ is affected by health $(H)$ through two distinct channels: first, health can influence an individual's productivity or real wage $(w)$, and second, independent of its effect on wages, health can influence the marginal rate of substitution between consumption goods and leisure (if we assume that health, consumption, and leisure are all directly valued by the individual). A host of other factors will also influence labor supply, including the price of consumption goods $\left(p_{c}\right)$, individual and family characteristics $(X)$ such as education, schooling, family background, and wealth, unexpected events $\left(e_{w}\right)$ such as weather shocks that influence labor demand, as well as unobservables such as ability $(\alpha)$ and tastes $(\xi)$.

\footnotetext{
${ }^{26}$ For household members who were away for an extended period, respondents were typically unable to provide information on hours worked in the past week. These individuals are excluded from the data analysis, as we discuss in the next section.
} 
Estimating the total effect of health in a reduced form equation for labor supply is difficult for well-known reasons that are discussed in the literature: bias from omitted variables (such as ability) that are correlated with both wages and health, simultaneity problems that arise from health and income influencing each other contemporaneously, and errors in the common measures of health. Since we are interested in estimating the reduced form effect of ARV treatment on labor supply, we overcome these problems by taking advantage of the panel structure of our data and the exogenous health improvement that occurs due to the provision of treatment. We now discuss the identification strategy and the reduced form equations that we use to estimate the labor supply response to ARV treatment. ${ }^{27}$

We identify the response to ARV therapy by examining changes in the treatment group's labor supply between rounds. Since labor supply is also influenced by several time-varying factors such as seasonality in agriculture (which influences local prices and labor demand) and aggregate health shocks (a greater malaria burden in specific months, for example), we include data from the random sample of adults to control for secular trends in the survey area. Thus, our key identifying assumption here is that data from the random sample control for the part of the ARV sample's labor supply trends that are due to factors other than treatment, such as seasonality. This strategy is similar to a difference-in-difference estimation strategy in which the "comparison group" is the sample of adults from the random sample. ${ }^{28}$ However, it should be noted that the labor supply trends in the random sample do not represent the counterfactual scenario of no treatment, and as such the reduced form empirical strategy we describe below estimates the treatment effect relative to baseline levels, but does not estimate the average treatment effect on the treated (the latter is discussed in Section VI.D). More formally, the reduced-form treatment response is identified by estimating individual fixed effects regressions in which a time interaction for ARV recipients measures the change in their labor supply between survey rounds:

$$
L_{i t}=\alpha_{i}+\beta_{1}\left(A R V_{i} * \operatorname{ROUND}_{t}\right)+\beta_{2} R O U N D 2_{t}+\sum_{\tau=1}^{10} \gamma_{\tau} M O N T H_{t}^{\tau}+\varepsilon_{i t} .
$$

$L_{i t}$ is the labor supply outcome of interest for individual $i$ in time $t$ (round 1 or 2), $\alpha_{i}$ is a fixed effect for individual $i$ that captures the effects of time-invariant variables like demographic characteristics, schooling, family background, as well as unobservables such as ability and tastes, $A R V_{i}$ is an indicator variable equal to one if individual $i$ is an ARV recipient, and $R O U N D 2_{t}$ indicates whether the observation is from round $2 .{ }^{29}$ The round 2 indicator and ten month-of-interview indicator variables (with one month from each round omitted to avoid singularity) together control for monthly fluctuations in labor supply in the

\footnotetext{
${ }^{27}$ In an earlier version of the paper (Thirumurthy, Graff Zivin, and Goldstein 2005), we also estimated labor supply regressions in which the length of time on ARV therapy was used as an instrument for health status (measured by the CD4 count or body mass index). This instrumental variables (IV) approach, which estimates the relationship between health and labor supply, confirms that the reduced-form results obtained in this paper are largely driven by the health improvements associated with ARV therapy. We pursue the reduced-form estimation strategy here, as it more closely resembles the policy experiment that most people have in mind when debating the merits of providing ARV therapy to people with AIDS in Africa.

${ }^{28}$ This also resembles the estimation strategy used by Jacobson, LaLonde, and Sullivan (1993). The authors use a longitudinal dataset to estimate the temporal pattern in earnings losses of displaced workers. In their estimation strategy, one reason why nondisplaced workers are used as a comparison group to displaced workers is that it is important to control for macroeconomic factors that can cause changes in workers' earnings.

${ }^{29}$ This equation could also be approximated without individual fixed effects as:
}

$$
L_{i t}=\alpha+\beta_{1} A R V_{i}+\beta_{2}\left(A R V_{i} * R O U N D 2_{t}\right)+\beta_{4} R O U N D 2_{t}+\sum_{\tau=1}^{10} \gamma_{\tau} M O N T H_{t}^{\tau}+\varepsilon_{i t}
$$

in which the level is assumed to vary systematically by ARV status. 
entire community. ${ }^{30}$ The coefficient of interest, $\beta_{1}$, measures the average change in labor supply between rounds due to the provision of ARV therapy.

The specification in equation 3 is designed to capture the average labor supply response to treatment between survey rounds for all ARV recipients in the sample. However, as noted earlier, patients have been on treatment for varying lengths of time during our round 1 interviews and the largest health improvement occurs during the first three months of treatment. We would therefore expect the largest labor supply changes between rounds to occur for patients in the early stages of treatment (assuming labor supply responds to health changes with only a short lag). Since the size of our ARV sample does not provide us with enough statistical power to estimate heterogeneous treatment responses using time on treatment in round 1 as a continuous variable, we employ a more parsimonious specification. We estimate a specification in which ARV recipients who were yet to begin treatment in round 1 or had been on ARVs for less than 100 days in round 1 (represented by $A R V_{i}^{<100}$ ) can experience a different change in labor supply between survey rounds than ARV recipients who had been on ARVs for more than 100 days in round $1\left(A R V_{i}^{>100}\right)$. This distinction divides the ARV sample into two roughly equal samples, and distinguishes between patients experiencing large and small health improvements. ${ }^{31}$ The following modified version of equation 3 is thus estimated:

$L_{i t}=\alpha_{i}+\beta_{1}\left(A R V_{i}^{<100} * R O U N D 2_{t}\right)+\beta_{2}\left(A R V_{i}^{>100} * R O U N D 2_{t}\right)+\beta_{4} R O U N D 2_{t}+\sum_{\tau=1}^{10} \gamma_{\tau} M O N T H_{t}^{\tau}+\varepsilon_{i t}$.

Equation 4 allows us to take advantage of variation in the amount of health improvement experienced by patients to establish whether there is a temporal pattern in the labor supply response to ARV treatment. ${ }^{32}$ While the primary identification strategy in equation 4 remains similar to equation 3 in that we use longitudinal data for the two treatment groups and correct for secular patterns in labor supply with data from the random sample, the interpretation of $\beta_{1}$ and $\beta_{2}$ as indicating the temporal pattern in the treatment effect relies on the assumption that the only important difference between these two groups is the time they have been "exposed" to ARV treatment. Of particular concern is the scenario under which

\footnotetext{
30 If the labor market impacts from ARV therapy were large enough to influence market wages (or local agricultural output prices), the random sample will also control for such aggregate effects. On the other hand, to the extent that certain aggregate health shocks disproportionately affect HIV-positive individuals such as the ARV recipients, data from the random sample alone will not adequately control for the labor supply effects of such shocks.

${ }^{31}$ The round 1 labor supply for patients in the $A R V^{<100}$ group can be thought of as approximating their baseline (time of treatment initiation) labor supply. Some individuals in this group began treatment before the Round 1 interview and may have experienced some improvements in health and labor supply before our initial interview, Others will be about to begin treatment and would have health status and labor supply that is higher than on the day of treatment initiation. For such individuals, the approach in equation 4 will likely underestimate the impact of treatment. For patients in the $A R V^{>100}$ group, the round 1 information represents their labor supply at a point in time that is well removed from the baseline date.

${ }^{32}$ Since 19 percent of the ARV recipients in our sample began treatment between rounds 1 and 2 (with nearly all of them beginning treatment within two months after round 1), it is possible to estimate treatment effects by exploiting within-person variation in treatment status during rounds 1 and 2 (that is, by including a stand-alone dummy variable $A R V_{i t}$ in equation 3). Given the concentration of health benefits within the first six months of treatment, we estimate heterogeneous treatment effects in equation 4 without including the dummy variable and instead treat individuals who are "close" to the start of treatment in round 1 as one group. As we note in Section 6, the results are robust to the inclusion of $A R V_{i t}$ in equations 3 and 4 . We do not divide this group into two groups (0-100 days as of round 1 and yet to start treatment as of round 1) because it also limits our statistical power to test for the impact of treatment when we examine sub-groups of male and female patients.
} 
those patients who began treatment long before round 1 are better informed or better connected than those who began treatment shortly before round 1 . This does not appear to be the case, as the AMPATH medical records reveal no significant differences in the health status of patients in the two groups (as revealed by the CD4 count) at the time of treatment initiation. We also find no significant differences in other important characteristics of patients in the two groups. Both are indistinguishable with respect to education, household size and demographic characteristics, distance to clinic, and wealth measures such as land and livestock holdings. ${ }^{33}$

While the division of ARV recipients into two samples will indicate whether there are heterogeneous responses during the post-treatment period, the use of 100 days as a cutoff for determining long and short duration of ARV therapy can be seen as arbitrary. ${ }^{34}$ To trace the response of labor supply more carefully, we construct indicators of whether or not the patient has been receiving ARVs for incremental durations of three months. The random sample is again used as a "comparison" group in this analysis to control for seasonality. Specifically, the following equation is estimated:

$L_{i t}=\alpha_{i}+\beta_{1} A R V_{i, t+3}+\beta_{2} A R V_{i, t-3}+\beta_{3} A R V_{i, t-6}+\beta_{4} A R V_{i, t-9}+\beta_{5} A R V_{i, t-12}+\beta_{6} A R V_{i, t-15}+\beta_{6} R O U N D 2_{t}+\sum_{\tau=1}^{10} \gamma_{\tau} M O N T H_{t}^{\tau}+$

$A R V_{i, t-\tau}$ indicates whether or not individual $i$ was receiving ARVs $\tau$ months prior to the interview at time $t$ (round 1 or round 2). In this specification, the outcomes of patients are compared at different times in the post-treatment period, with the period of three months before and after treatment initiation serving as the omitted time period. ${ }^{35}$ Due to the relatively small number of patients in our sample who have been on treatment for more than 18 months, we do not add an additional term to capture the marginal effect of treatment during the post-18 month period, but instead allow it to be captured by the coefficient for the $A R V_{i, t-5}$ term. Data from adults in the random sample again control for secular trends in the labor market.

The individual fixed effects in all of the equations estimated will allow for ARV recipients to have different levels of labor supply than other adults in the sample. While time varying factors such as seasonality are dealt with using the time indicators, the key assumption in identifying the treatment response is that the ARV recipients in the sample do not have characteristics that influence the change in labor supply between rounds. The only form of heterogeneity in the treatment response allowed by the equations above is in the temporal pattern of the response. In the analysis below, however, we also test for heterogeneity in the treatment response according to the gender of the ARV recipient.

\footnotetext{
${ }^{33}$ For each of these observed characteristics, we conducted t-tests and were unable to reject the hypothesis that the means for the two groups of ARV recipients are equal.

${ }^{34}$ While the specific choice of 100 days is arbitrary, the results obtained from estimating equation 5 suggest a rather narrow range of candidate cutoff values. In unreported analyses, we have also estimated our primary specification (equation 4) using cutoffs ranging from 90 - 110 days and our results remain unchanged.

35 Note that the definition of the indicator variables implies that the coefficients are marginal effects of completing additional months of ARV therapy. That is, patients who have completed 6-9 months of ARV therapy will experience an average increase in labor supply (relative to the three months before and after initiation) that is equal to $\beta_{2}+\beta_{3}$. Also, the term $\mathrm{ARVt}+3$ is included to estimate differences in labor supply in periods that are more than three months before the initiation of treatment.
} 


\section{Results for Adult Patients' Labor Supply Response}

We restrict the analysis of labor supply to individuals between the ages of 18 and 65 who appear in both rounds. ${ }^{36}$ Table 4 presents summary statistics from the first round for 191 adult ARV recipients and 1,286 adults in the random sample. ${ }^{37}$ Crop farming is the primary economic activity of households in the survey area, as 84 percent of the random sample adults and 60 percent of adult ARV recipients reported having worked on their farm in the past seven days. A non-trivial fraction of adults also report working off-farm for a wage (17-18 percent) or in a household enterprise (16-17 percent).

Table 4 shows that in the first round, ARV recipients are significantly more likely to not have done any work in the past week (24 percent of ARV recipients compared to 11 percent of adults in the random sample). ARV recipients also work significantly fewer hours than other adults, unconditional on participating in the labor force ( 24 hours compared to 35 hours) and conditional on participating ( 32 hours compared to 40 hours). Table 5 summarizes the respondents' reported reasons for not having worked in the past week. Only eight percent of unemployed adults in the random sample report being sick as the reason for not having worked. In contrast, being sick is the reported reason for 85 percent of unemployed adult ARV recipients. It is also interesting to note that the percentage of all random sample individuals not working for reasons other than illness is more than twice the figure for all ARV patients.

The data also show the importance of controlling for seasonal variations in labor supply. Figure 5 plots the average weekly hours worked in each month of the survey. There is a peak during the maize planting and harvesting seasons - the months of April and May (in round 1) and November through January (in round 2), respectively. ${ }^{38}$ Because of the seasonality in agriculture and the reliance of most people on self-employed farming, for the most part we do not focus on outcomes such as income or wages. ${ }^{39}$ Instead, most of our analysis below examines individuals' labor force participation and hours worked.

\section{A. Individual Fixed Effects Results}

To identify the impacts of ARV treatment between the two survey rounds, we estimate labor supply regressions with individual fixed effects, as discussed in Section V. Table 6 reports results from estimating equations 3 and 4 . We find that ARV therapy leads to a large and statistically significant increase in labor supply. Adults receiving treatment are 8.5 percentage points more likely to participate in the labor force in round 2 than in round 1 (column 1), controlling for time-varying factors that are evident in both the ARV sample and

\footnotetext{
36 Adults who move into the household between rounds are thus excluded. Also, we exclude 115 adults who migrate out of the household permanently before round 2 or who live in households that were not found in round 2 (this includes the ARV recipients who were lost-to-follow-up by AMPATH). Finally, 43 adults are excluded because the respondent for the labor supply questionnaire did not know, in at least one round, how many hours the adult worked in the past week (possibly because the person migrated temporarily). Rates of absence from round 2 due to reasons other than mortality do not differ significantly for ARV recipients and adults in the random sample. Even when we control for age, sex, and education, ARV recipients are not significantly more likely to be absent during the second round. The role of attrition due to mortality is discussed in Section VI.C.

${ }^{37}$ Household members of the ARV recipients are not included in any of this analysis. To the extent that labor supply of these adult household members is affected by the changing health status of the ARV recipient, pooling them with adults in the random sample may produce biased results.

${ }^{38}$ The month of August appears as an exception, but this is likely due to the fact that relatively few individuals were interviewed during that month (when round 1 was concluding). The median for this month is considerably lower, at 38 hours.

${ }^{39}$ Due to the seasonality of agriculture, income tends to be concentrated after harvest periods. We find that household income shows a sharp peak during December and January, when most households sell maize after the annual harvest (not reported). It is therefore not very meaningful to compare changes in income between rounds. Furthermore, agricultural income is often only attributed to the household head (and more rarely, the spouse), even if multiple persons in the household work on the farm or contribute to a family business. Since treated patients are not always the household head or spouse, the income reported for that person is not always a good indication of the person's productivity nor is it highly correlated with their hours worked. Therefore, it is not surprising that income differences in Table 4 between ARV recipients and all other adults are not statistically significant.
} 
the random sample. Hours worked in the past week also increases significantly between survey rounds, by 4.6 hours (column 2). Relative to the levels in round 1, this implies a large increase in labor supply for the entire sample of ARV patients: labor force participation rates rise by almost 11 percent, and weekly hours worked rise by 19 percent.

Columns 3 and 4 of Table 6 show a stronger and even more striking result. The individuals with by far the largest increase in labor supply between the two rounds are patients who began receiving ARVs less than 100 days prior to the round 1 interview (a group that includes some individuals who began receiving ARV therapy shortly after round 1). The magnitude of these increases is substantial: over the course of six months, patients who have just initiated ARV therapy show a 17 percentage point increase in labor force participation rates and a 7.9 hour increase in hours worked. ${ }^{40}$ Given round 1 labor supply levels of 65.1 percent and 20.3 hours for this group, the estimates imply a 26 percent increase in participation rates and a 39 percent increase in hours worked. In contrast, the other ARV recipients in our sample show no statistically significant change in outcomes between rounds. ${ }^{41}$ This temporal pattern in the labor supply response among treated patients very closely resembles the health responses (in BMI and CD4 count) reported in Section IV.

Since the regressions of hours worked includes individuals not participating in the labor force during round 1 , the results do not clearly establish whether the labor supply response is also applicable to patients already working in round 1 . In column 5 of Table 6 , we present results for a restricted sample that includes only those adults who were participating in the labor force during round 1 . Since we do not find a statistically significant effect on hours worked, the results suggest that the main treatment response occurs on the extensive margin of labor supply--allowing patients who were previously too sick and incapable of working to enter the labor force.

The results for ARV patients who have just initiated treatment are noteworthy since these patients are particularly sick before starting treatment and at the time of the round 1 interview. As discussed earlier, in the absence of treatment these patients have a small probability of living for another six months, until the round 2 interview date. In this sense, the estimated labor supply responses are likely to be underestimates of the impact of treatment on the treated. ${ }^{42}$

Table 7 reports the results from estimating equation 5, with a more complete set of indicators to identify the temporal response to treatment. As columns 1 and 2 show, the increase in labor supply is largest during the first three to six months of ARV therapy, with subsequent increases being smaller and statistically insignificant. The point estimates show that after three to six months on treatment, there is a 12.4 percentage point increase in labor force participation rates (but not statistically significant at the ten percent level) and a statistically significant increase of 7.3 hours in weekly hours worked. Compared to levels of labor supply for patients who are within three months before or after initiation of ARV therapy (the omitted group), this implies a 20 percent increase in the labor force participation rate and a 37 percent increase in hours worked. ${ }^{43}$

\footnotetext{
40 When we allow patients on treatment for 0-100 days in round 1 to have a separate change in labor supply than patients who begin treatment between rounds 1 and 2 (the treatment effect for the latter group being estimated by adding at $A R V_{i t}$ term to equation 4), we find that both groups have identical and significant changes in labor force participation rates and that patients who begin treatment after round 1 have a slightly larger increase in hours worked.

${ }^{41}$ Comparisons of socio-economic characteristics of the two groups of ARV recipients show that there are no statistically significant differences in the gender, education, and household characteristics such as household size and ownership of land and livestock (results not reported). This implies that such characteristics cannot explain the large difference in the labor supply changes of the two groups.

${ }^{42}$ Because HIV/AIDS is a chronic disease where the health of AIDS patients (those in the later stages of the disease) steadily declines in the absence of treatment, the typical problem of mean reversion in the outcome variable (Ashenfelter and Card 1985) does not apply here and therefore does not bias the estimates.
} 


\section{B. Decomposition of the Impact of ARV Therapy}

The composition of adults' economic activities exhibits considerable variation according to gender and seasons of the year. Moreover, households with ARV patients are less likely to be engaged in farming for reasons that may have to do with their past health history and lower landholdings. In light of such differences, this section examines changes in labor supply more carefully, focusing on the composition of economic activities and differences between men and women.

Composition of Activities-Instead of using an aggregate measure of labor supply, we estimate equation 4 separately for each of the three different types of labor supply that were recorded in the survey: wage labor, farm labor, non-farm business labor. Data from adults in the random sample are used to control for seasonal patterns in each of the labor activities. The results in columns $1-3$ of Table 8 indicate that much of the increase in labor supply occurs in non-farm business work. Patients are more likely to begin doing wage labor and farm labor as well, but these increases are not statistically significant. All of these increases appear to occur among patients who are in the early stages of treatment in round 1 . The absence of a significant increase in farm work (which arguably requires the most physical labor) is noteworthy and seems to suggest that ARV therapy does not restore the ability of patients to do physical labor. However, when we limit our analysis to households that own three or more acres of land, ARV recipients are found to experience a significant increase in the likelihood of having done own-farm work and in hours worked on the farm. Thus, the lack of an aggregate treatment effect on farm work appears to be driven by the presence of ARV households with small landholdings.

The results for monthly income from each of the three labor activities (columns 4-6 in Table 8) underscore the significance of seasonality in interpreting income patterns. While farm income is known to be highly seasonal, non-farm business income is less variable during the year. As a result, business income should be more responsive to short-term changes in health status. Indeed, we find there is a statistically significant increase in non-farm business income for ARV recipients in the early stages of treatment (column 6 in Table 8).

Labor Supply Impacts by Gender-The survey data from each round show that men are more likely to be engaged in labor market activities in the past week than women. In results not reported, we also find gender differences for some components of labor supply: women are much less likely to work for a wage, but equally likely to work in a non-farm business. Thus it is possible that the impacts of ARV therapy on labor supply will differ according to the gender of the patient and the comparison group used. To test for such differences, we estimate equation 4 separately for men and women.

As columns 1 and 2 of Table 9 show, for male patients in the early stages of treatment, there is no significant increase in labor force participation rates but a large and significant increase of 12.7 hours in weekly labor supply between rounds (a 43 percent increase relative to their average weekly hours worked in round 1). This suggests that among male patients, those already working prior to initiation of treatment are the ones who increase their labor supply after treatment. For women in the early stages of treatment, there is a large and significant increase of 21.8 percentage points in the labor force participation rate between rounds (a 35 percent increase relative to their average participation rate in round 1), but no significant increase in weekly hours worked. Combining these results with round 1 observations provides an intuitive explanation for this pattern. Since men have high levels of participation

\footnotetext{
${ }^{43}$ For adult ARV recipients in our sample who have been on ARV therapy for fewer than three months, the labor force participation rate is 61.56 percent and the average weekly hours worked is 19.68 .
} 
to begin with, most of their response to improved health takes the form of additional hours worked. For women, initial participation is low, so labor supply is the natural margin for change.

\section{Controlling for Attrition in the ARV Sample}

Since our analysis so far has excluded ARV recipients who do not appear in our sample for both rounds, the estimated labor supply responses apply only to those ARV patients who survived and continued to come to the clinic until round 2. The average response to ARV therapy for all treated patients is therefore likely to be smaller.

In the ARV sample, mortality of patients and loss to follow-up are the main reasons for attrition of individuals (and households) between the two rounds of the survey. For patients who were interviewed at the HIV clinic in round 1 but subsequently died or were lost to follow-up, we were unable to obtain any household information in round 2. Patients who are lost to follow-up can be assumed to have either stopped seeking HIV care altogether, transferred to another clinic, or died (these patients have an average CD4 count of 79 at the time of the round 1 interview). Of the 217 adult ARV recipients in our sample from round 1, ten patients are known to have died before round 2, and another seven patients were not found in round 2 (due to loss to follow-up).

A conservative approach to estimating the average labor supply response to ARV therapy is to analyze the panel data while treating these attrited patients as individuals with zero labor supply in round 2 . Since it is unlikely that all patients lost-to-follow-up are dead or not working in the labor market, this strategy provides us with a lower bound on the labor supply response. ${ }^{44}$ As Table 10 shows, we find that even with the inclusion of zero labor supply for patients who are deceased or lost to follow-up (columns 3 and 4), there is a large and statistically significant increase in labor supply. All patients who had been on ARVs for fewer than 100 days in round 1 experienced an 11.1 percentage point increase in labor force participation rates and a 6.7 hour increase in weekly hours worked (compared to 17.0 percentage points and 7.9 hours in Table 6 , for the analysis without attrited patients). In regressions not reported here, we also use our rich dataset of observable characteristics to model the attrition of individuals and then re-weight the sample using the inverse probability weights (IPW) technique described in Fitzgerald, Gottschalk and Moffitt (1998) and Wooldridge (2002) ${ }^{45}$ Our main results reported in Section VI.A are robust to the use of these estimation strategies.

The reduced effectiveness of ARV therapy when it is initiated in very sick patients has been widely reported in the literature (Hogg et al. 2001; Wools-Kaloustian et al. 2006). Rates of progression to death are considerably higher when baseline CD4 counts are below 100/ $\mathrm{mm}^{3}$, thus compromising the short-term effectiveness of ARV therapy. In fact, for the nine patients in our sample who died between round 1 and 2 and for whom a baseline CD4 count can be obtained in the AMRS, the average baseline CD4 count was $35.5 / \mathrm{mm}^{3}$ (and the average round $1 \mathrm{CD} 4$ count was $53 / \mathrm{mm}^{3}$ ). This influences how to interpret the role of mortality in our analysis. While our earlier results should be recognized as being valid only for patients who survive, the broader relevance of these results is heightened if HIV-positive patients begin receiving treatment before having advanced to late stages of the disease (as

\footnotetext{
${ }^{44}$ Attrited patients who have not died may be receiving care at other clinics. Alternatively, patients from far away may have missed several appointments and therefore not been included in the round 2 sample.

${ }^{45}$ Specifically, this is done by using observed characteristics in round 1 including gender, age, education, marital status and health measures (such as CD4 count) to predict the probability that a person is observed for the second time in round 2 . The inverse of the predicted probabilty then serves as the weight given to an observation in the labor supply regressions.
} 
will be the case when ARV treatment programs are scaled-up and become more established).

\section{Estimating the Impact of Treatment on the Treated}

As noted earlier, there is strong evidence that the health of individuals who have developed AIDS will decline rapidly without treatment, generally leading to death in less than one year (Morgan et al. 2002; Chequer et al. 1992). Since the baseline CD4 counts of patients in our sample are well below $200 / \mathrm{mm}^{3}$ (the level associated with developing AIDS), very few of the patients would be working (or even alive) in round 2 without treatment. While this counterfactual case is not observed by us, we can provide an upper bound of the impact of treatment on the treated by assuming that without treatment, all patients in the sample would not be participating in the labor force in round 2. While the 'true' impact of treatment lies somewhere between our earlier estimates and the upper bound figures presented in this section, the clinical evidence on disease progression suggests that the true impact will be only slightly below the upper bound. Comparing the observed treated group to this constructed control group, we can obtain difference-in-difference estimates of the treatment impact. For patients who are just beginning treatment in round 1, the impact of ARV therapy on labor supply is very large: an increase in the labor force participation rate of 85.4 percentage points, and an increase in hours worked of 26 hours (not reported). This represents a 5-fold increase in participation and a 4-fold increase in hours worked relative to our earlier estimates of the labor supply response to treatment (in Table 6). Moreover, this suggests that our earlier results are considerable underestimates of the true impact of treatment on the treated. While our earlier results are useful in understanding how labor supply responds to health improvements among previously sick AIDS patients, the fact that they are underestimates of the treatment impact should be borne in mind when evaluating treatment interventions. In the concluding section of the paper, we use this estimated impact of treatment on the treated to provide a rough comparison of the costs and benefits of ARV therapy.

\section{Response of Family Labor Supply to ARV Therapy}

Intrahousehold reallocation of time is known to be an important consumption smoothing mechanism of households in low-income countries. In settings with imperfect financial markets, households often adjust the time spent by children and adults in activities such as schooling, housework, and employment in response to sudden changes in income and health. These adjustments can have differential effects according to the age and gender of household members. For example, Jacoby and Skoufias (1997) find that children's school attendance in rural India is responsive to seasonal fluctuations in income. Similarly, Chetty and Looney (2007) show that unemployment shocks in Indonesia lead to large decreases in households' consumption levels and expenditures on children's education. In the context of our study, sudden changes in the income of adults (for better or worse, as would be the case with and without treatment, respectively) can therefore have long-lasting welfare consequences if children's time allocation to schooling is affected. Other studies have examined time allocation to household activities and labor market activities in response to income and health shocks, finding that responses depend on the gender of household members (Pitt and Rosenzweig 1990; Kochar 1995). Such evidence from developing countries suggests that ARV therapy can also influence the labor supply of patients' family members. Having estimated a large increase in patients' labor supply due to ARV therapy (own-effect of health), this section examines the labor supply of children and adults in the patients' households (cross-effects of health).

There is a large theoretical and empirical literature on the role of income and substitution effects in individual time allocation decisions (beginning with Becker 1965) and family 
labor supply (beginning with Ashenfelter and Heckman 1974). A simple model of family labor supply can be used to illustrate the role of ARV therapy in influencing labor supply within the family. Two effects are likely to be especially relevant. First, as the treated patient begins to work, there is an income effect for the family. Since leisure is a normal good, the cross-income effect within the family is negative and the increase in patient income leads other household members to work less. Second, as the treated patient's health improves, the time demanded for taking care of the patient and performing additional housework is diminished, thereby expanding other household members' time endowment for work and leisure. Since this "reduced caregiving" or "time release" effect exerts a positive influence on the labor supply of the patients' family members, the net effect of treatment on family members' labor supply is theoretically ambiguous. There is also a third, cross-substitution effect on family members' labor supply (in response to an income-compensated change in the patient's market productivity), which further complicates the household response. In the standard model of family labor supply, this effect can be positive or negative depending on whether the nonmarket times of the treated patient and the other family member are complements or substitutes, respectively.

To estimate the net effect of treatment on child and adult labor in ARV households, we examine longitudinal data on the labor supply of non-patient individuals in these households and use data from random sample households to control for monthly fluctuations in labor supply. Specifically, the following equation is estimated with longitudinal data for nonpatient individuals in ARV households and others in the random sample:

$L_{i h t}=\alpha_{i}+\beta_{1}\left(A R V H H_{<100, h^{*}} R O U N D 2_{t}\right)+\beta_{2}\left(A R V H H_{>100, h} * R O U N D 2_{t}\right)+\beta_{3} R O U N D 2_{t}+\sum_{\tau=1}^{10} \gamma_{\tau} M O N T H_{t}^{\tau}+\varepsilon_{i h t}$

$L_{i h t}$ is the labor supply measure of interest for individual $i$ in household $h$ at time $t$ (round 1 or 2), $\alpha_{i}$ is a fixed effect for individual $i, \operatorname{ROUND}_{t}$ indicates whether the observation is from round 2, and $A R V H H_{<100, h}$ and $A R V H H_{>100, h}$ are indicator variables equal to one if household $h$ has an adult who was receiving ARV therapy for less than or more than 100 days, respectively, at the time of the round 1 interview. We estimate equation 6 separately for men, women, and young and old boys and girls.

Table 11 presents summary statistics from the first round for children and adults in ARV households and random sample households (excluding HIV-positive patients at the Mosoriot HIV clinic). A large fraction of boys and girls in the random sample had engaged in some labor market activities during the past week (78 percent and 74 percent, respectively), although the mean number of hours is considerably lower than for adults. ${ }^{46}$ In general, household members of ARV patients are equally or less likely to be working than others in the random sample, although the cross-sectional comparisons can be misleading given differences in wealth, education, and other characteristics between the two groups of households.

\footnotetext{
${ }^{46}$ The mean hours worked by children are low enough to be consistent with regular school attendance, which will be examined in subsequent work.
} 
Table 12 contains results from estimating equation 6. Panel A reports results for the labor supply of men and women. As column 1 shows, soon after initiation of ARV treatment for adult patients, there is a negative but insignificant change in the labor force participation rates of adults in the patients' households. For women in these households, the decline in labor supply is greater- 15.0 percentage points-and almost significant at the ten percent level (column 3). This suggests that, at the margin, women are more likely to compensate for changes in the AIDS patients' labor supply by entering and exiting the labor force. As men are generally more likely to remain in the labor force at all times, we do not observe any significant adjustment of their labor force participation decisions (column 2).

Panels B and C of Table 12 contain results for the labor supply of boys and girls, respectively. We examine responses among young and old children (8-12 years and $12-18$ years) separately to capture potentially heterogeneous responses among them. The results indicate that there is a large decline in the labor supply of young boys after an adult household member begins to receive ARV therapy, but no significant change for older boys. Girls do not significantly change their labor supply, regardless of age. Column 2 of the Panel $\mathrm{B}$ shows that the decline in labor supply for younger boys in ARV households occurs gradually. In households with an adult who began receiving treatment shortly before round 1 , the decline in labor force participation rates of young boys is 14.6 percentage points but not statistically significant. However, in households with adults who began receiving treatment more than 100 days before round 1, labor force participation rates decline by 21.5 percentage points and this coefficient is statistically significant. Hours worked also declines significantly for younger boys, with a reduction of 8.5 hours in households exposed to treatment for more than 100 days at the time of round 1. Given that boys in ARV households have an average labor force participation rate of 74 percent and average weekly hours worked of 12.3 hours in round 1 , the estimates in Table 12 imply extremely large declines in labor supply between round 1 and round $2 .{ }^{47}$

All else equal, young children in Kenya are less likely to be engaged in economic activities since there are no official school fees for primary school and the productivity of young children is likely to be low. Older boys, on the other hand, are considerably more likely to be engaged in economic activities and less likely to be enrolled in school (Central Bureau of Statistics 2004; Beegle 2005). This may explain why, at the margin, young boys are more likely to be pulled into the labor force when adults become very sick and then pulled out of the labor force when the adults become healthy. ${ }^{48}$ Given that girls allocate fewer hours to labor market activities and more hours to housework, ARV therapy is more likely to exert its influence on their time allocation in the domain of housework (not measured in labor supply), especially since adult women in the household appear to be adjusting their labor supply in response to disease and treatment.

Another way of examining the influence of ARV therapy on household members' labor supply is to take advantage of variation in the number of treated adults in ARV households. In nine percent of the ARV households, there are two adult patients receiving ARV therapy. These households are much more heavily burdened by AIDS in the months prior to round 1 and experience larger health improvements between rounds than households with only one ARV patient. Thus, we examine whether there are larger changes in labor supply in these ARV household by estimating the following equation:

\footnotetext{
${ }^{47}$ Given strong divisions of labor along gender lines in our survey region, we might also expect the effect of treatment to depend on the gender of both the treated patient and the child of interest. Unfortunately, since nearly 75 percent of adult ARV recipients in our sample are women, there is not enough statistical power to examine such effects.

${ }^{48}$ Future research will examine whether there are corresponding changes in school enrollment or attendance for boys.
} 


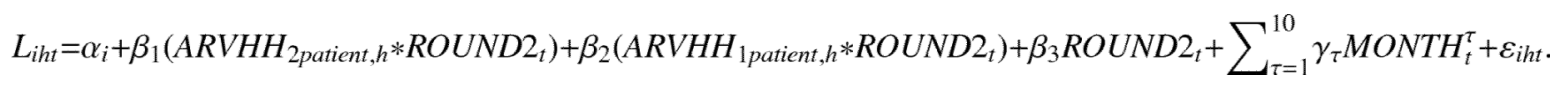

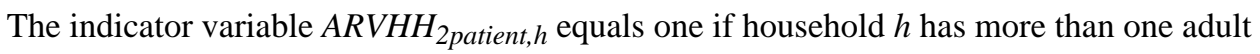
ARV recipient and zero otherwise. Likewise, $A R V H H_{\text {lpatient }, h}$ equals one if household $h$ has only one adult ARV recipient.

The results from estimating equation 7 are presented in Table 13. In panel A, we find that in double-patient households there are large and statistically significant declines over time in the number of hours worked in the past week by both men and women. In single-patient households, however, hours worked by adults do not change significantly. Panel B shows that for boys of all ages, there is a much larger decline in labor supply in the double-patient households than the single-patient households (columns 1 and 2). For young boys in doublepatient households, the decline in labor force participation is 75.6 percentage points, as compared to 13.2 percentage points in single-patient households (column 2). Hours worked by young boys in all ARV households also declines significantly, and the responses are again larger in double-patient households (column 5). For older boys in double-patient households, there is a significant decline in both labor force participation and hours worked (columns 3 and 6). Older boys in single-patient households, however, do not experience any significant change in labor supply. Finally, Panel C shows that the labor supply of girls does not change significantly in both types of households.

These results suggest that in households with multiple adults who have developed AIDS, other household members (particularly boys and adults) are forced to do considerably more market work before treatment is initiated, possibly in the place of the patient. Upon initiation of treatment, these household members are able to work less. More generally, in contrast to the large positive changes in the labor supply of treated patients, the results in this section always show zero or negative changes in the labor supply of patients' household members. These results suggest that the income effect from the higher labor supply of treated patients is larger than the time release effect that comes from the treated patient no longer being sick, thus allowing some household members to decrease their labor supply. They also suggest that households are engaged in their customary function of smoothing total market and nonmarket labor supply over time as they face the negative health shock of AIDS and the offsetting, positive health shock from ARV therapy. An important implication of these results is that ARV therapy influences outcomes of not just the treated patient but also individuals living with the patient.

\section{Conclusion}

This paper provides the first evidence on how ARV therapy affects the labor supply of AIDS patients and their household members. Using data from our household survey, we find that patients have significantly higher labor supply within six months after the initiation of treatment. This response is also large, with patients showing a 20 percent increase in labor force participation rates and a 35 percent increase in hours worked. We also find that the treatment effects for female patients are primarily on the extensive margin (participation), while male patients primarily experience changes in the intensive margin of labor supply 
(hours). Importantly, these results suggest that with treatment, the labor supply of AIDS patients can recover rapidly from periods of severe illness. We also find evidence that the labor supply of patients' family members (particularly young boys) declines after initiation of treatment. This suggests that family members may have been compensating for previously sick patients' diminished labor supply and that they too experience some of the benefits from treatment. These effects are larger and impact more household members in multiple-patient families. Taken together, the results providence evidence that ARV therapy has significant non-health benefits and influences a range of intrahousehold decisions.

In the absence of data from a randomly chosen sample of AIDS patients who do not receive ARV therapy, it will be difficult to estimate the full impact of treatment on the treated. Given ethical constraints to implementing such an evaluation, our strategy represents the best available method of estimating the response to treatment while controlling for important confounding factors (such as seasonality in labor supply). Moreover, especially for the case of patients' labor supply, we argue that our results are underestimates of the treatment effect because there is considerable medical evidence that untreated AIDS patients will die very quickly. Our conclusion that treatment results in significantly higher labor supply would only be strengthened if the analysis were based on comparison to a true counterfactual group.

Although the number of HIV-positive individuals requiring ARV therapy will continue to grow during the next decade, treatment programs have yet to be scaled up in many countries. The results presented in this paper are therefore highly relevant for evaluating such interventions. In fact, the labor supply response we have estimated can provide an important first step in analyzing the costs and benefits of ARV therapy. Median daily wage rates for all adults doing casual wage labor in our sample are 100 Kenya shillings, or about $\$ 1.50$. Since this daily wage is associated with six hours of work, the hourly wage is about 17 Kenya shillings, or $\$ 0.25$. Using our base case estimates of a 6.9 hour average increase in weekly hours worked, treatment can thus be expected to yield an average wage benefit to patients of $\$ 86$ per year (assuming individuals work 50 weeks per year). This estimate is based on the labor supply impact relative to pre-treatment labor supply. However, for the purpose of a cost-benefit evaluation, it is essential to calculate benefits using the impact of treatment on the treated - based on a comparison to counterfactual outcomes rather than pre-treatment outcomes. Using our upper bound of the treatment impact (calculated by assuming that patients would have zero labor supply within six months if treatment were not provided), the average increase in weekly hours worked is 26 hours. In this case the average wage benefit to patients from treatment is $\$ 325$ per year, which is considerably larger than the $\$ 150$ annual per-patient cost of first-line ARV drugs. In addition to ARV drug expenditure, however, there are several additional costs associated with providing treatment, such as the costs of lab tests, treatment for opportunistic infections, clinic space, and medical personnel. AMPATH estimates these costs to be approximately $\$ 200$ per-patient. Thus, the total patient wage benefit from providing treatment is roughly equal to the total cost of drugs and other associated expenses.

However, these are only the simple private wage gains for the patients. Since treatment expands the time endowment of patients by reducing sick time, patients are also consuming more leisure. Moreover, while the reduced market labor supply of children due to the provision of treatment does represent a loss in market income for the household, it is likely that the increased nonmarket activities of these household members have greater private value to the household as a whole. As a result, the fact that children reduce their labor supply suggests that the benefit of treatment is larger than the income gain from the parent's increased supply of labor (and leisure). In line with the severity of HIV/AIDS, these results underscore the importance of maintaining a broad perspective when analyzing the costs and 
benefits of ARV treatment - looking at the intrahousehold allocation of labor is only a first step. The social benefits from treatment are likely to exceed the private benefits, but valuing them is a non-trivial challenge. As a result, one purpose of the rough cost-benefit calculations presented above is to show that the private benefits from treatment alone can cover the costs of treatment. Indeed, the large labor supply responses we find here are not the only socio-economic outcomes likely to be affected by ARV therapy. Both HIV/AIDS and treatment can be expected to influence many other aspects of life within patients' households. Additional analysis of our data suggests important effects on the nutritional status of children living with ARV recipients. Schooling and other forms of investment may also be affected, especially since we find that the incidence of child labor decreases due to treatment. All of these responses will contribute to an understanding of the comprehensive welfare consequences of ARV therapy. A detailed analysis of these other non-health outcomes is part of our future research agenda.

\section{Acknowledgments}

This project would not have been possible without the support of the Academic Model for Prevention and Treatment of HIV/AIDS (AMPATH) and members of the IU-Kenya partnership. We have benefited from discussions with Richard Akresh, Michael Boozer, Joseph Altonji, Janet Currie, Germano Mwabu, Matt Neidell, T. Paul Schultz, Tavneet Suri, Christopher Udry, and participants in seminars at the Center for Global Development, the International Food Policy Research Institute, Michigan State University, RAND, University of Maryland, University of Pittsburgh, Yale University, the Center for Interdisciplinary Research on AIDS at Yale, and the World Bank. We would also like to thank Bill Evans and two anonymous referees for invaluable comments. The household survey was implemented under the direction of Mabel Nangami and the authors. Giovanna d'Adda assisted in managing the second round of the survey and the data collection was facilitated by the excellent field supervision of Irene Muhunzu. We also acknowledge the tremendous contributions of Andrew Anyembe, Caroline Amuyunzu, Jayne Chaina, Norbert Ketter, James Mungai, June Ochanda, and Jacklyne Tetee for administering questionnaires; and Chelimo Cherono, David Marende, Maurice Mungai, Florence Oduor, and Martha Simiyu for computer entry of questionnaires. We thank Kara Wools-Kaloustian and Beverly Musick for guidance in using the AMPATH medical records. Financial support for this project was received from the Economic and Social Research Council (UK), Pfizer, Inc., The World Bank, Yale University's Center for Interdisciplinary Research on AIDS (CIRA) through a grant from the National Institute of Mental Health to Michael Merson, M.D. (No. P30 MH 62294), the Social Science Research Council, and the Calderone Program at Columbia University. The views expressed here do not necessarily reflect those of the World Bank or its member countries. The household survey data used in this article can be obtained beginning December 2008 through December 2011 from Harsha Thirumurthy, School of Public Health, Box 7411, University of North Carolina at Chapel Hill, Chapel Hill, NC 27510, harsha@unc.edu. The medical data used in this article are the property of AMPATH treatment program and can only be obtained by direct permission from them. Interested researchers should contact William Tierney, Regenstrief Institute, Inc., Health Information and Translational Sciences Bldg. (HITS), 410 West 10th Street, Suite 2000, Indianapolis, IN 46202, wtierney@iupui.edu.

\section{References}

Ashenfelter, Orley; Heckman, James. The Estimation of Income and Substitution Effects in a Model of Family Labor Supply. Econometrica. 1974; 42(1):73-86.

Ashenfelter, Orley; Card, David. Using the Longitudinal Structure of Earnings to Estimate the Effect of Training Programs. Review of Economics and Statistics. 1985; 67(4):648-60.

Becker, Gary. A Theory of the Allocation of Time. Economic Journal. 1965; 75(299):493-517.

Beegle, Kathleen. Labor Effects of Adult Mortality in Tanzanian Households. Economic Development and Cultural Change. 2005; 53(3):655-83.

Bell, Clive S.; Devarajan, Shanta; Gersbach, Hans. World Bank Policy Research Working Paper Series No 3152. 2003. Long Run Economic Costs of AIDS: Theory and Application to South Africa.

Campaign for Access to Essential Medicines. Untangling the Web of Price Reductions: A Pricing Guide for the Purchase of ARVs for Developing Countries. Geneva: Medecins Sans Frontieres; 2005 June 8. Available at http://www.accessmed-msf.org

Canning, David. The Economics of HIV/AIDS in Low-income Countries: The Case for Prevention. Journal of Economic Perspectives. 2006; 20(3):121-42. [PubMed: 17176527] 
Central Bureau of Statistics. Kenya 1999 Population and Housing Census. Nairobi: Central Bureau of Statistics; 1999.

Central Bureau of Statistics. Kenya Demographic and Health Survey 2003. Central Bureau of Statistics; Nairobi: 2004.

Chequer P, et al. Determinants of Survival in Adult Brazilian AIDS Patients, 1982-1989. AIDS. 1992; 6(5):483-7. [PubMed: 1616654]

Chetty, Raj; Looney, Adam. Income Risk and the Benefits of Social Insurance: Evidence from Indonesia and the United States. In: Ito, Takatoshi; Rose, Andrew K., editors. Fiscal Policy and Management: NBER East Asia Seminar on Economics. 16. Chicago: University of Chicago Press; 2007.

Coetzee, David, et al. Outcomes After Two Years of Providing Antiretroviral Treatment in Khayelitsha, South Africa. AIDS. 2004; 18(6):887-95. [PubMed: 15060436]

Cohen, Jonathan, et al. Addressing the Educational Void During the Antiretroviral Therapy Rollout. AIDS. 2004; 18:2105-6. [PubMed: 15577641]

Collaborative Group on AIDS Incubation and HIV Survival including the CASCADE EU Concerted Action. Time from HIV-1 Seroconversion to AIDS and Death Before Widespread Use of HighlyActive Antiretroviral Therapy: A Collaborative Re-analysis. Lancet. 2000; 355(9210):1131-7. [PubMed: 10791375]

Einterz, Robert M., et al. Responding to the HIV Epidemic: The Power of an Academic Medical Partnership. Academic Medicine. 2007; 82(8):812-8. [PubMed: 17762264]

Fitzgerald, John; Gottschalk, Peter; Moffitt, Robert. An Analysis of the Impact of Sample Attrition on the Second Generation of Respondents in the Michigan Panel Study of Income Dynamics. Journal of Human Resources. 1998; 33(2):251-99.

Fox, Matthew P., et al. The Impact of HIV/AIDS on Labour Productivity in Kenya. Tropical Medicine and International Health. 2004; 9(3):318-24. [PubMed: 14996359]

Goldstein, Markus, et al. HIV/AIDS and Socio-economic Status: Preliminary Evidence from Western Kenya. Mimeo: Yale University; 2005.

Grubb, Ian; Perriens, Jos; Schwartlander, Bernhard. A Public Health Approach to Antiretroviral Treatment: Overcoming Constraints. Geneva: WHO; 2003.

Gutierrez, Juan Pablo, et al. Achieving the WHO/UNAIDS Antiretroviral Treatment 3 by 5 Goal: What Will it Cost? Lancet. 2004; 364(9428):63-4. [PubMed: 15234857]

Hammer, Scott M., et al. A Controlled Trial of Two Nucleoside Analogues Plus Indinavir in Persons with Human Immunodeficiency Virus Infection and CD4 Cell Counts of 200 Per Cubic Millimeter or Less. New England Journal of Medicine. 1997; 337(11):725-33. [PubMed: 9287227]

Hogg, Robert S., et al. Improved Survival Among HIV-infected Individuals Following Initiation of Antiretroviral Therapy. Journal of the American Medical Association. 1998; 279(6):450-4. [PubMed: 9466638]

Hogg, Robert S., et al. Rates of Disease Progression by Baseline CD4 Cell Count and Viral Load after Initiating Triple-drug Therapy. Journal of the American Medical Association. 2001; 286(20): 2568-77. [PubMed: 11722271]

Jacoby, Hanan G.; Skoufias, Emmanuel. Risk, Financial Markets, and Human Capital in a Developing Country. Review of Economic Studies. 1997; 64(3):311-35.

Jacobson, Louis S.; LaLonde, Robert J.; Sullivan, Daniel G. Earnings Losses of Displaced Workers. American Economic Review. 1993; 83(4):685-709.

Kochar, Anjini. Explaining Household Vulnerability to Idiosyncratic Income Shocks. American Economic Review Papers and Proceedings. 1995; 85(2):159-64.

Koenig, Serena P.; Leandre, Fernet; Farmer, Paul E. Scaling-up HIV Treatment Programmes in Resource-limited Settings: The Rural Haiti Experience. AIDS. 2004; 18(S3):S21-5. [PubMed: 15322480]

Kremer, Michael. Pharmaceuticals in the Developing World. Journal of Economic Perspectives. 2002; 16(4):67-90. [PubMed: 15179979]

Laurent, Christian, et al. The Senegalese Government's Highly Active Antiretroviral Therapy Initiative: An 18-month Follow-up Study. AIDS. 2002; 16(10):1363-70. [PubMed: 12131213] 
Lee, Lisa M, et al. Survival After AIDS Diagnosis in Adolescents and Adults During the Treatment Era, United States, 1984-1997. JAMA. 2001; 285(10):1308-15. [PubMed: 11255385]

Lemp George F, et al. Survival Trends for Patients with AIDS. JAMA. 1990; 263(3):402-6. [PubMed: 2294307]

Mamlin, Joe, et al. Academic Institutions Linking Access to Treatment and Prevention: Case Study. Geneva: WHO; 2004.

Marins, Jose Ricardo P, et al. Dramatic Improvement in Survival Among Adult Brazilian AIDS Patients. AIDS. 2003; 17(11):1675-82. [PubMed: 12853750]

Marseille, Elliot; Hofmann, Paul B.; Kahn, James G. HIV Prevention Before HAART in Sub-Saharan Africa. Lancet. 2002; 359(9320):1851-6. [PubMed: 12044394]

Morgan, Dilys, et al. HIV-1 Infection in Rural Africa: Is There a Difference in Median Time to AIDS and Survival Compared with that in Industrialized Countries? AIDS. 2002; 16(4):597-603. [PubMed: 11873003]

Pitt, Mark; Rosenzweig, Mark. Estimating the Iintrahousehold Iincidence of Iillness: Cchild Hhealth and Ggender-inequality in the Aallocation of Ttime. International Economic Review. 1990; 31(4): 969-89.

Palella, Frank J., et al. Declining Morbidity and Mortality Among Patients with Advanced Human Immunodeficiency Virus Infection. New England Journal of Medicine. 1998; 338(13):853-60. [PubMed: 9516219]

Ruger, Jennifer Prah; Jamison, Dean; Bloom, David. Health and the Economy. In: Merson, Michael; Black, Robert; Mills, Anne, editors. International Public Health: Diseases, Programs, Systems and Policies. Gaithersburg, Maryland: Aspen Publishers, Inc; 2001.

Strauss, John; Thomas, Duncan. Health, Nutrition, and Economic Development. Journal of Economic Literature. 1998; 36(2):766-817.

Thirumurthy, Harsha; Zivin, Joshua Graff; Goldstein, Markus. NBER Working Paper \#11871. 2005. The Economic Impact of AIDS Treatment: Labor Supply in Western Kenya.

Thomas, Duncan; Frankenberg, Elizabeth. Health, Nutrition and Prosperity: A Microeconomic Perspective. Bulletin of the World Health Organization. 2002; 80(2):106-13. [PubMed: 11953788]

UNAIDS. 2006 Report on the Global AIDS Epidemic. Geneva: Joint United Nations Programme on the HIV/AIDS; 2006.

Wools-Kaloustian, Kara, et al. Viability and Effectiveness of Large-scale HIV Treatment Initiatives in Sub-Saharan Africa: Experience from Western Kenya. AIDS. 2006; 20(1):41-8. [PubMed: 16327318]

WHO. World Health Organization Technical Report Series. 1995. Physical Status: The Use and Interpretation of Anthropometry. Report of a WHO Expert Committee; p. 854

WHO. Scaling Up Antiretroviral Therapy in Resource-Limited Settings: Guidelines for a Public Health Approach. Geneva: WHO; 2002.

WHO. Treating 3 Million by 2005: Making it Happen: The WHO Strategy. Geneva: WHO; 2003.

WHO. Progress on Global Access to HIV Antiretroviral Therapy: A Report on "3 by 5" and Beyond. Geneva: WHO; 2006.

Wooldridge, Jeffrey. Inverse Probability Weighted M-estimators for Sample Selection, Attrition, and Stratification. Portuguese Economic Journal. 2002; 1(2):117-39.

Yamano, Takashi; Jayne, TS. Measuring the impacts of working-age adult mortality on small-scale farm households in Kenya. World Development. 2004; 32(1):91-119.

Young, Alwyn. The Gift of the Dying: The Tragedy of AIDS and the Wealth of Future African Generations. Quarterly Journal of Economics. 2005; 120(1):423-466. 


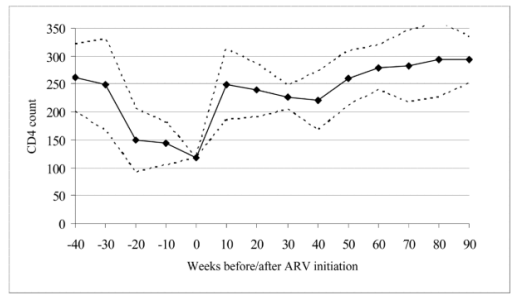

Figure 1. CD4 Count Before and After Initiation of ARV Therapy

Notes: Figure is generated using CD4 count data in the AMPATH Medical Records System for all patients receiving ARV therapy at the Mosoriot HIV Clinic. The figure shows the average CD4 count (solid line) in ten week intervals prior to each point in time before or after treatment initiation. The figure also shows the 95 percent confidence intervals (dashed lines) obtained from estimating a linear regression of individuals' CD4 counts on dummy variables for each interval (with the omitted interval being the ten weeks prior to treatment initiation). 


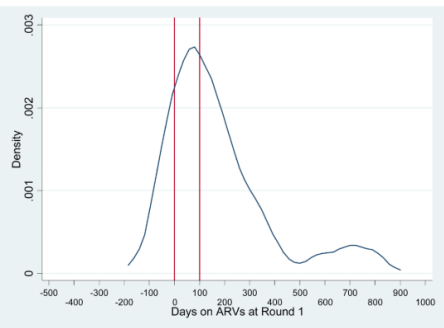

Figure 2. Density of Days on Treatment as of Round 1 Interview

Notes: Figure is generated using the date of treatment initiation and the date of the round 1 interview. Vertical bars are shown at 0 days and 100 days. The sample consists of the 191 ARV recipients who appear in both rounds of the household survey data. 


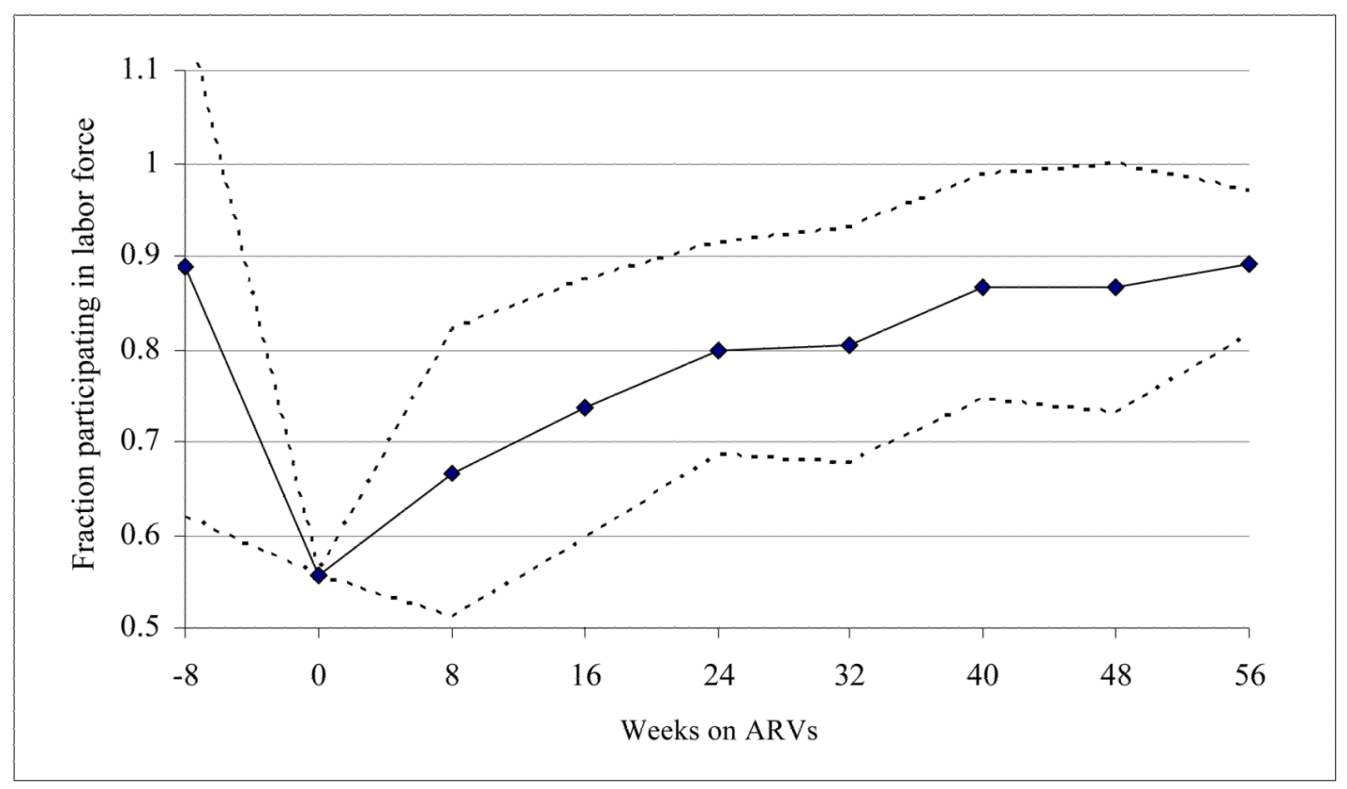

Figure 3. Labor Force Participation Rates Before and After ARV Therapy

Notes: Figure is generated using authors' survey data and shows the average labor force participation rate (solid line) in eight week intervals prior to each point in time before or after treatment initiation. The figure also shows the 95 percent confidence intervals (dashed lines) obtained from estimating a linear regression of individuals' labor force participation on dummy variables for each interval (with the omitted interval being the eight weeks prior to treatment initiation). The sample consists of the 191 ARV recipients who appear in both rounds of the household survey data. 


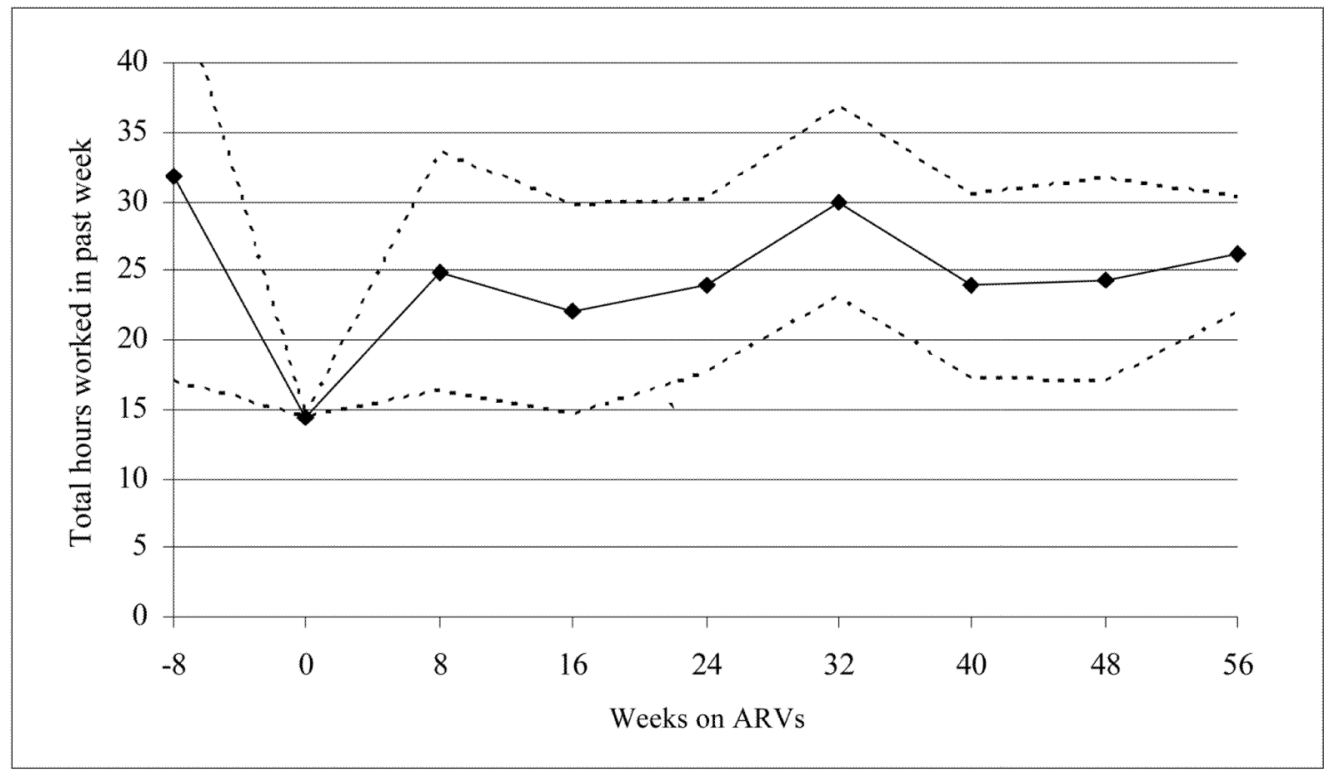

Figure 4. Weekly Hours Worked Before and After ARV Therapy

Notes: Figure is generated using authors' survey data and shows the average number of hours worked in the past week (solid line) in eight week intervals prior to each point in time before or after treatment initiation. The figure also shows the 95 percent confidence intervals (dashed lines) obtained from estimating a linear regression of individuals' hours worked on dummy variables for each interval (with the omitted interval being the eight weeks prior to treatment initiation). The sample consists of the 191 ARV recipients who appear in both rounds of the household survey data. 


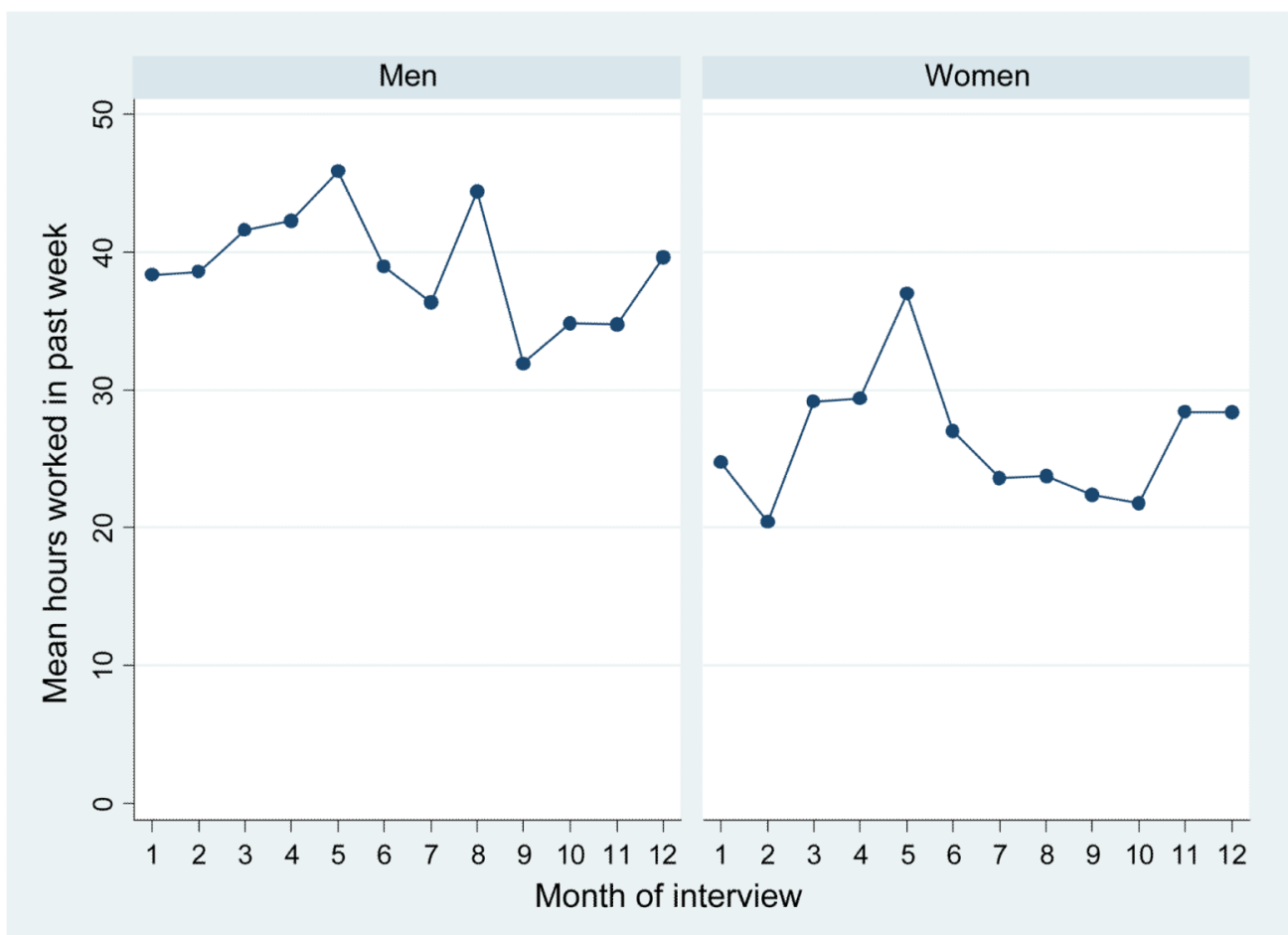

Figure 5. Weekly Hours Worked by Month of Interview (Men and Women in Random Sample) Notes: Figure is generated using authors' survey data and shows the average number of hours worked in the past week by men (left panel) and women (right panel) according to the month in which the interview was conducted. The sample used consists of all individuals in the random sample between the ages of 18-65 years. 
Table 2

Impact of ARV therapy on CD4 count and BMI

\begin{tabular}{lcc}
\hline & (1) & (2) \\
\hline Dependent variable: & CD4 & BMI \\
\cline { 2 - 3 } & \multicolumn{2}{c}{ Patient fixed effects } \\
\cline { 2 - 3 } On ARVs at least 1 month & & $0.38(2.65)^{* * *}$ \\
On ARVs at least 2 months & & $0.18(1.18)$ \\
On ARVs at least 3 months & $126.72(10.60)^{* * *}$ & $-0.10(0.61)$ \\
On ARVs at least 4 months & & $0.21(1.29)$ \\
On ARVs at least 5 months & & $0.06(0.43)$ \\
On ARVs at least 6 months & $-9.11(0.55)$ & $0.45(3.25)^{* * *}$ \\
On ARVs at least 7 months & & $0.29(2.46)^{* *}$ \\
On ARVs at least 8 months & & $0.30(2.14)^{* *}$ \\
On ARVs at least 9 months & $41.34(2.31)^{* * *}$ & $0.53(3.71)^{* * *}$ \\
On ARVs at least 10 months & & $0.14(0.93)$ \\
On ARVs at least 11 months & & $0.22(1.45)$ \\
On ARVs at least 12 months & $7.45(0.37)$ & $0.27(1.79)^{* *}$ \\
On ARVs at least 15 months & $38.71(1.31)$ & $0.08(0.50)$ \\
On ARVs at least 18 months & $0.42(0.01)$ & $0.09(0.52)$ \\
Constant & $87.48(12.56)^{* * *}$ & $19.53(275.93)^{* * *}$ \\
Observations & 458 & 2678 \\
R-squared & 0.80 & 0.87 \\
\hline
\end{tabular}

Notes: Absolute value of t-statistics in parentheses (* significant at 10\%; ** significant at 5\%; *** significant at $1 \%$ ). Dependent variables are the CD4+ T cell count (column 1) and body mass index (column 2). Regressions include patient fixed effects. The regressions include all available post-treatment measures of the CD4 count and BMI for the ARV recipients in our sample. Since not all patients in our sample have one or more measures of these outcomes, the number of patients used in the regressions is less than the 191 ARVrecepients in our sample. 


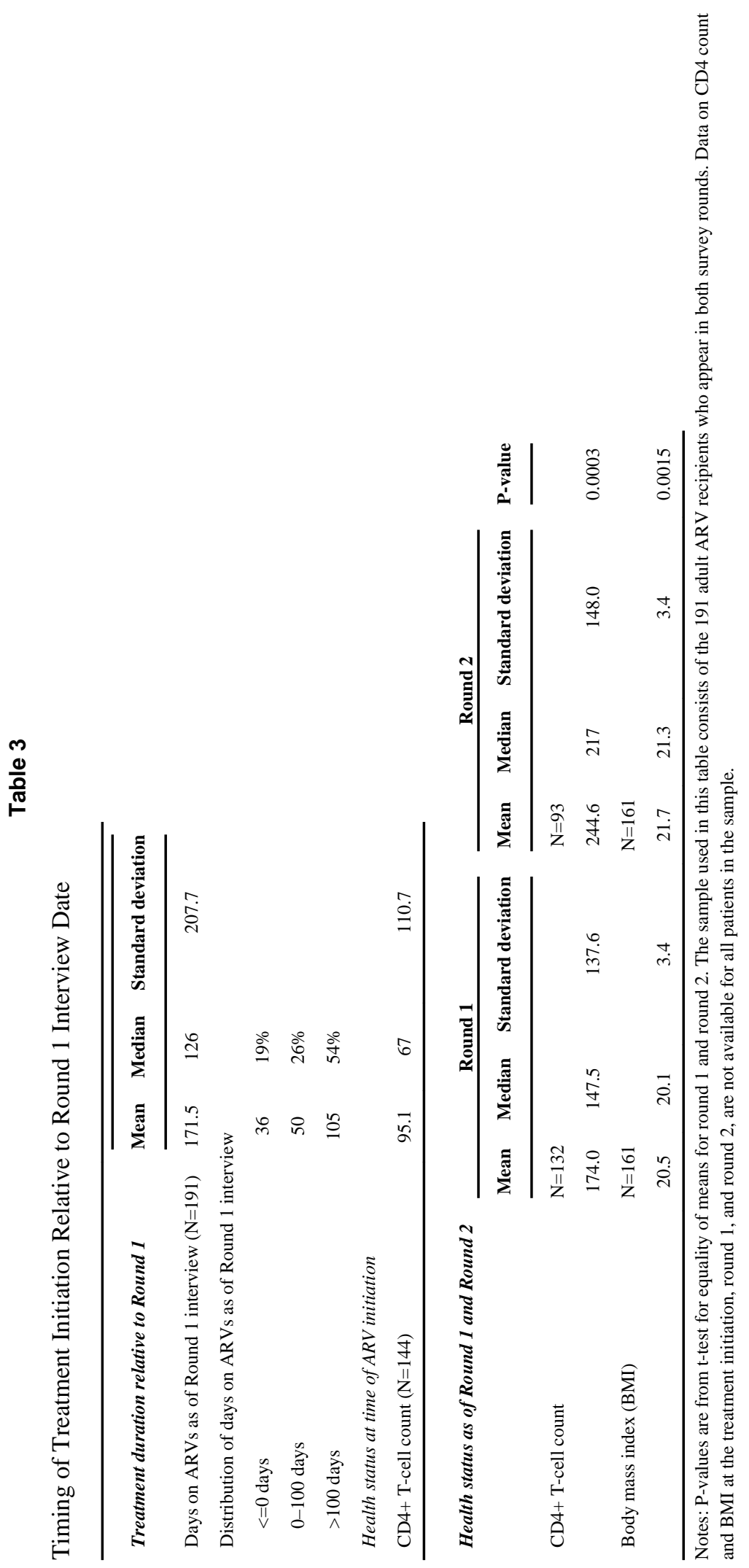


Table 5

Reported Reasons for Not Working in the Past Week (Round 1 only)

\begin{tabular}{lccc}
\hline & Random sample & & ARV patients \\
Sample size (adults 18-65 years) & 1286 & & 191 \\
Did no work in past week & $10.8 \%$ & & $24.1 \%$ \\
Reported reason for not working in past week & $(\mathrm{N}=138)$ & & $(\mathrm{N}=46)$ \\
Sick & $8 \%$ & $85 \%$ \\
Student & $54 \%$ & $0 \%$ \\
Housework & $12 \%$ & $0 \%$ \\
No work available & $7 \%$ & $7 \%$ \\
Other & $18 \%$ & $9 \%$ \\
\hline
\end{tabular}




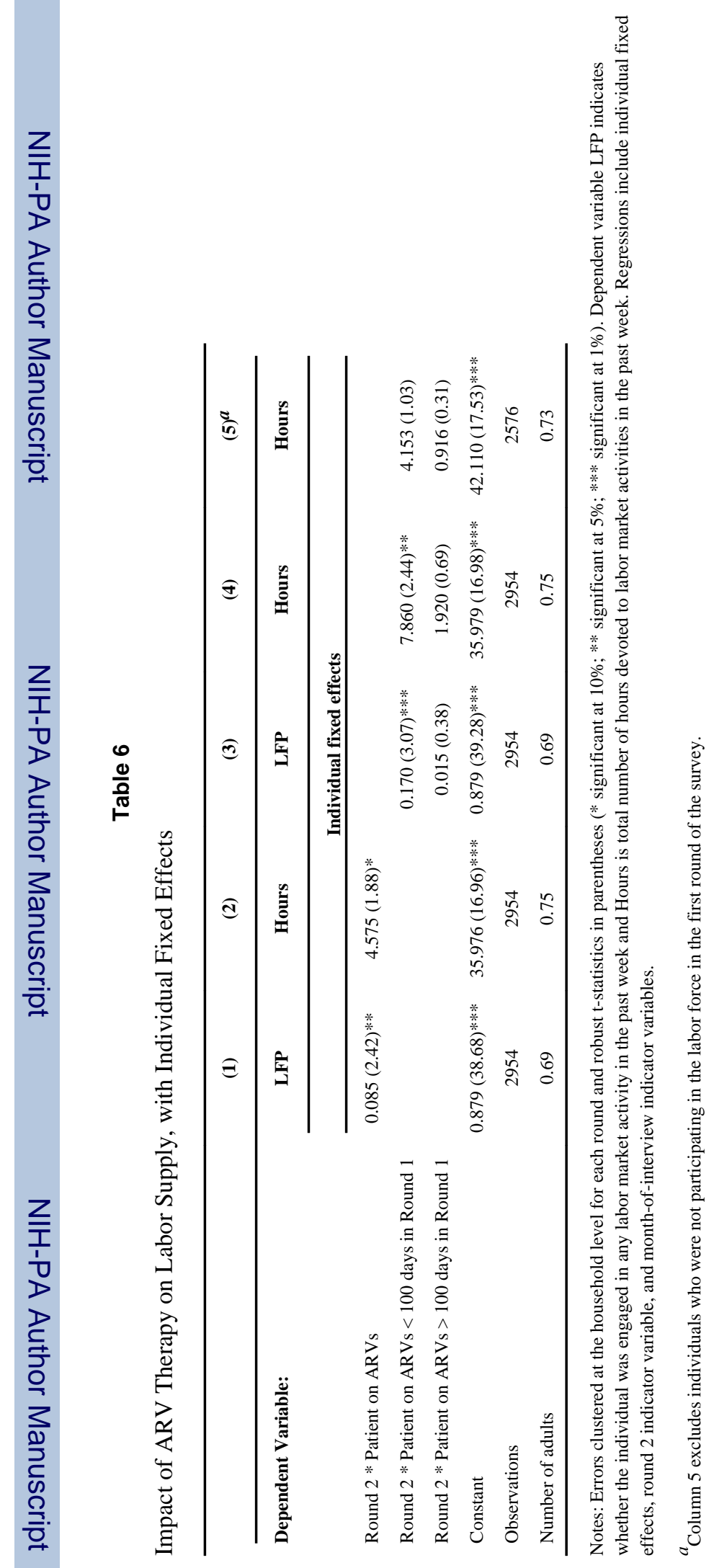

J Hum Resour. Author manuscript; available in PMC 2011 December 14. 
Table 7

Estimating the Timepath of Labor Supply after Initiation of ARVs

\begin{tabular}{lcc}
\hline & (1) & (2) \\
\hline Dependent Variable: & LFP & Hours \\
\cline { 2 - 3 } & Individual fixed effects \\
\cline { 2 - 3 } 3 months prior to ARV initiation & $0.083(1.36)$ & $-2.292(0.25)$ \\
On ARVs at least 3 mths ago & $0.124(1.61)$ & $7.277(2.09)^{* *}$ \\
On ARVs at least 6 mths ago & $0.090(1.10)$ & $0.438(0.11)$ \\
On ARVs at least 9 mths ago & $-0.024(0.30)$ & $-0.476(0.11)$ \\
On ARVs at least 12 mths ago & $-0.072(0.72)$ & $-2.402(0.39)$ \\
On ARVs at least 15 mths ago & $0.106(0.95)$ & $3.741(0.69)$ \\
Constant & $0.870(37.71)^{* * *}$ & $35.625(16.56)^{* * *}$ \\
Observations & 2954 & 2954 \\
R-squared & 0.69 & 0.75 \\
\hline
\end{tabular}

Notes: Errors clustered at the household level for each round and robust t-statistics in parentheses (* significant at $10 \%$; ** significant at 5\%; *** significant at $1 \%$ ). Dependent variable LFP indicates whether the individual was engaged in any labor market activity in the past week and Hours is total number of hours devoted to labor market activities in the past week. Regressions include individual fixed effects, round 2 indicator variable, and month-of-interview indicator variables. 


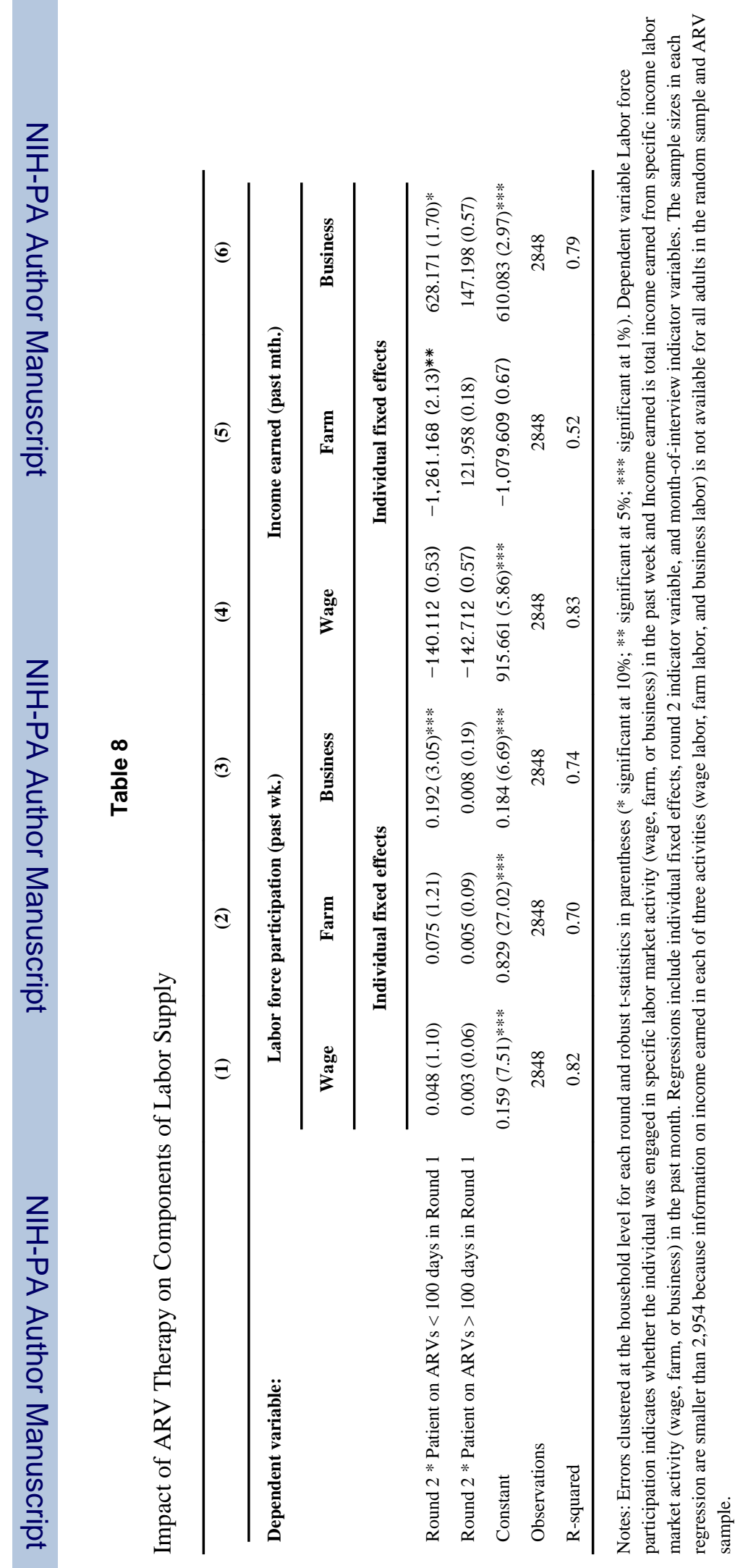

J Hum Resour. Author manuscript; available in PMC 2011 December 14. 
Table 9

Impact of ARV Therapy for Men and Women

\begin{tabular}{|c|c|c|c|c|}
\hline \multirow[t]{3}{*}{ Dependent variable: } & LFP & Hours & LFP & Hours \\
\hline & \multicolumn{2}{|c|}{ Men } & \multicolumn{2}{|c|}{ Women } \\
\hline & \multicolumn{4}{|c|}{ Individual fixed effects } \\
\hline Round $2 *$ Patient on ARVs $>100$ days in Round 1 & $0.028(0.32)$ & $4.564(0.69)$ & $0.018(0.36)$ & $-0.368(0.12)$ \\
\hline Constant & $0.896(28.95)^{* * *}$ & $44.164(14.47)^{* * *}$ & $0.852(25.83)^{* * *}$ & $29.476(12.15)^{* * *}$ \\
\hline Observations & 1408 & 1408 & 1546 & 1546 \\
\hline
\end{tabular}

Notes: Errors clustered at the household level for each round and robust t-statistics in parentheses $(*$ significant at $10 \%$; ** significant at 5\%; *** significant at 1\%). Dependent variable LFP indicates whether the individual was engaged in any labor market activity in the past week and Hours is total number of hours devoted to labor market activities in the past week. Regressions include individual fixed effects, round 2 indicator variable, and month-of-interview indicator variables. 
Table 10

Impact of ARV Therapy With Attritors in the ARV Sample

\begin{tabular}{|c|c|c|c|c|}
\hline \multirow[t]{2}{*}{ Dependent variable: } & LFP & Hours & LFP & Hours \\
\hline & \multicolumn{4}{|c|}{ Individual fixed effects } \\
\hline Sample includes: & \multicolumn{2}{|c|}{ deceased } & \multicolumn{2}{|c|}{ deceased \& lost to FUP } \\
\hline Round $2 *$ Patient on ARVs $>100$ days in Round 1 & $-0.011(0.26)$ & $1.530(0.56)$ & $-0.012(0.28)$ & $1.542(0.57)$ \\
\hline Constant & $0.876(38.83)^{* * *}$ & $35.825(16.79) * * *$ & $0.874(38.36)^{* * *}$ & $35.700(16.67)^{* * *}$ \\
\hline Observations & 2974 & 2974 & 2988 & 2988 \\
\hline
\end{tabular}

Notes: Errors clustered at the household level for each round and robust t-statistics in parentheses (* significant at 10\%; ** significant at 5\%; *** significant at 1\%). Dependent variable LFP indicates whether the individual was engaged in any labor market activity in the past week and Hours is total number of hours devoted to labor market activities in the past week. Regressions include individual fixed effects, round 2 indicator variable, and month-of-interview indicator variables. 


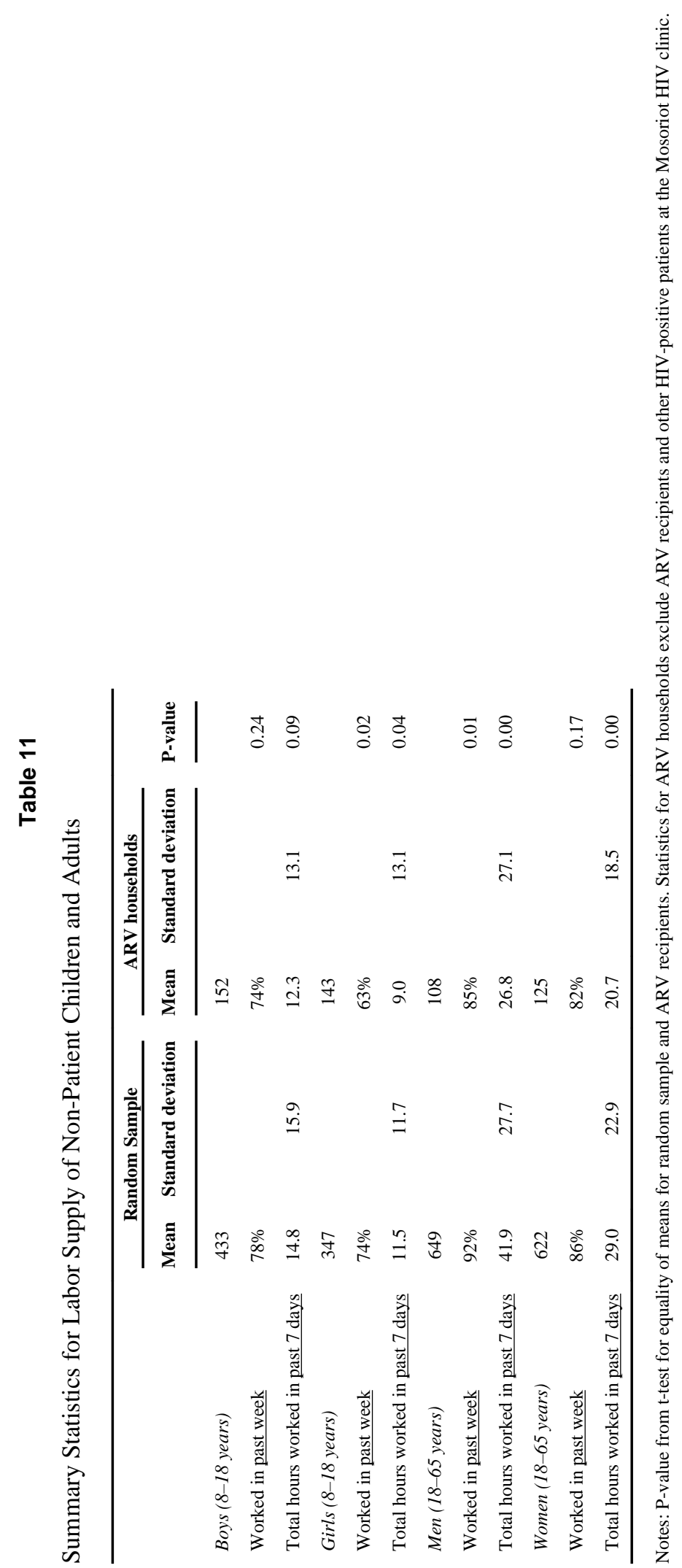

J Hum Resour. Author manuscript; available in PMC 2011 December 14. 


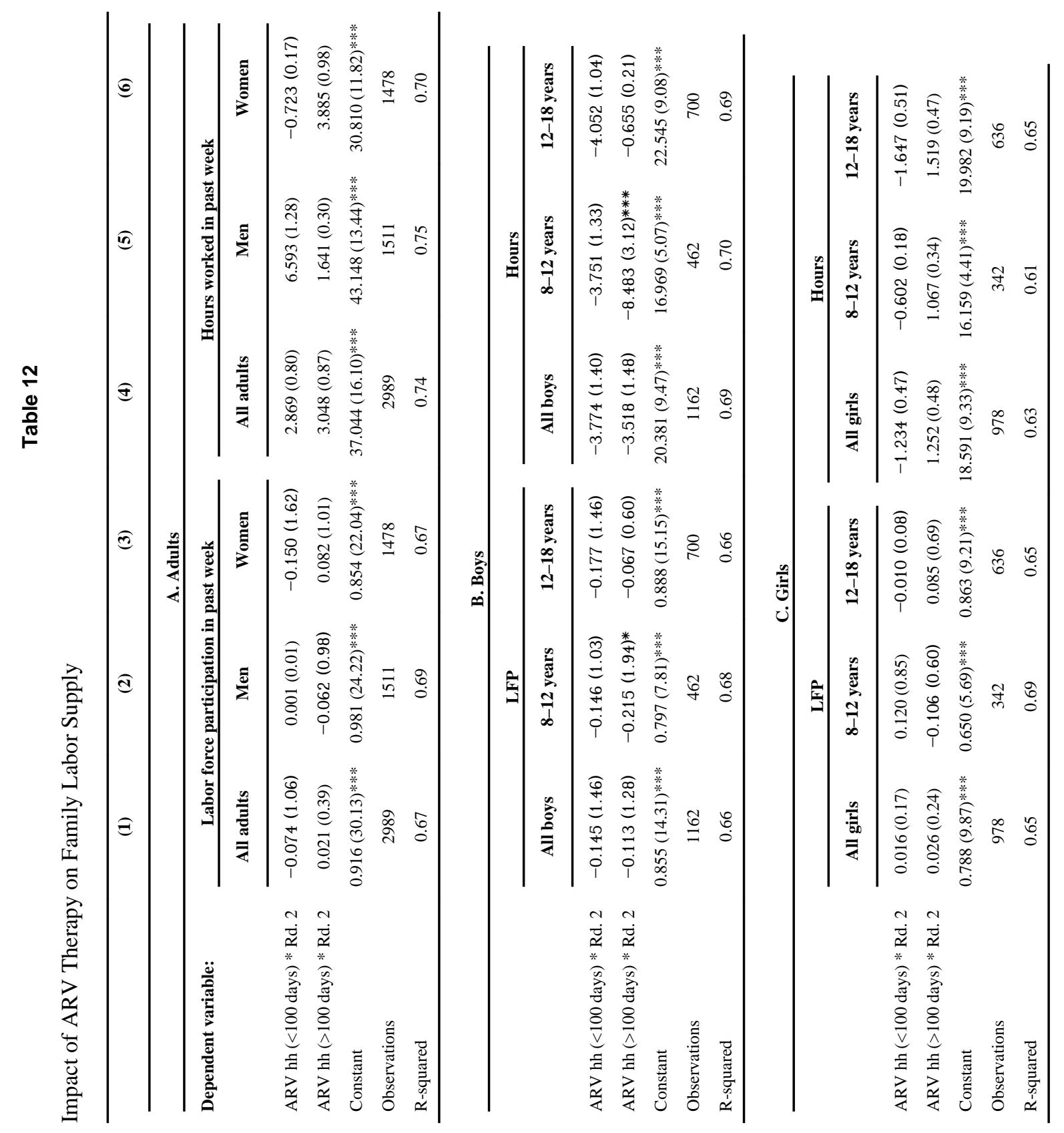




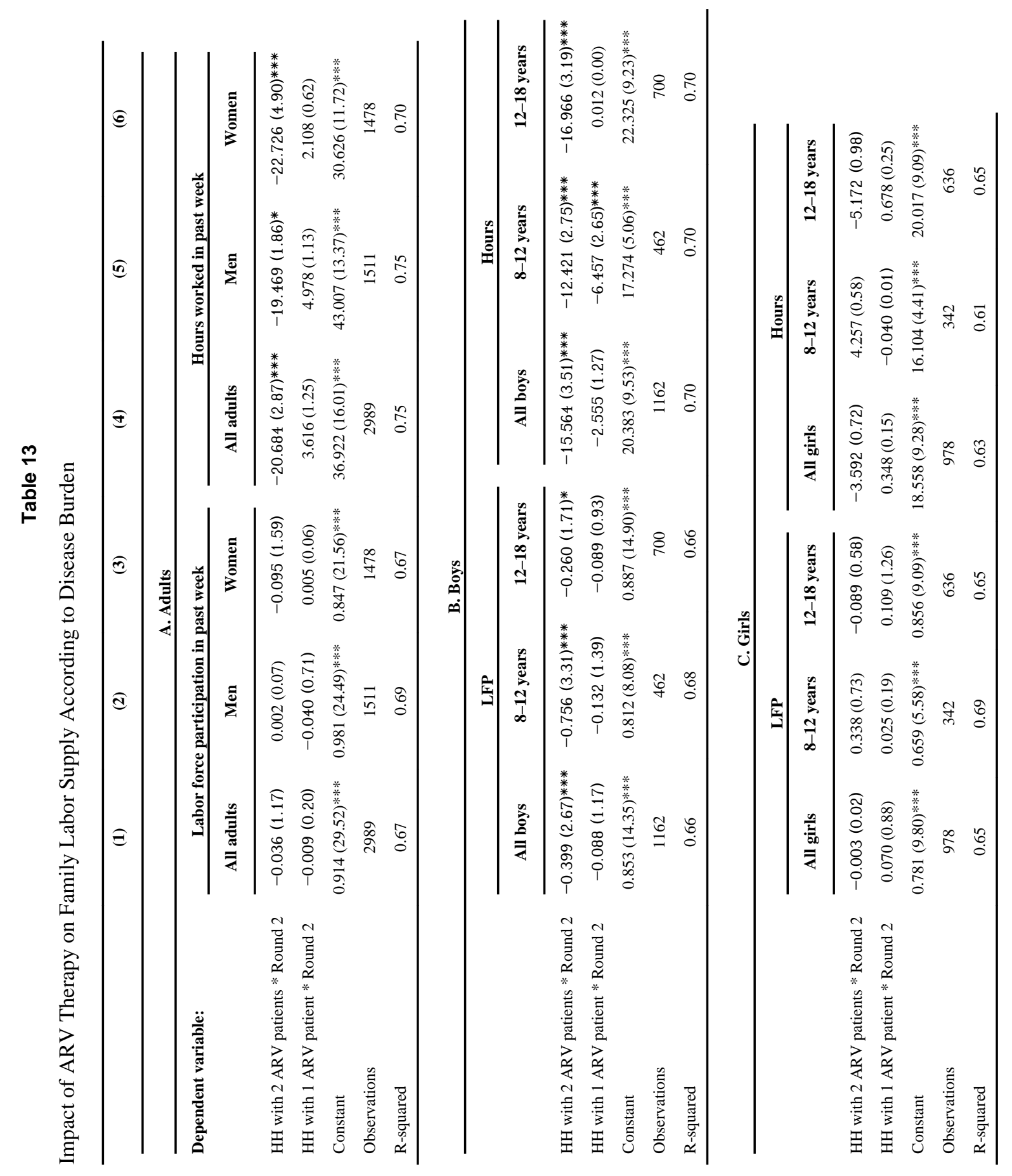

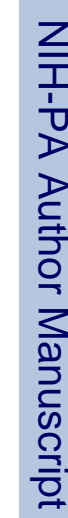

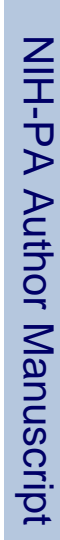

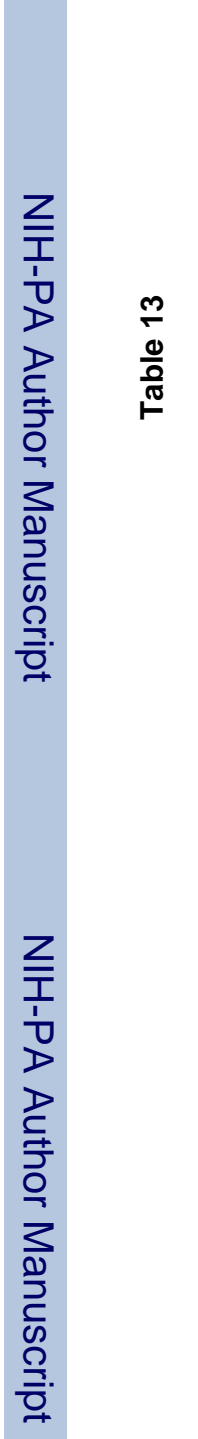

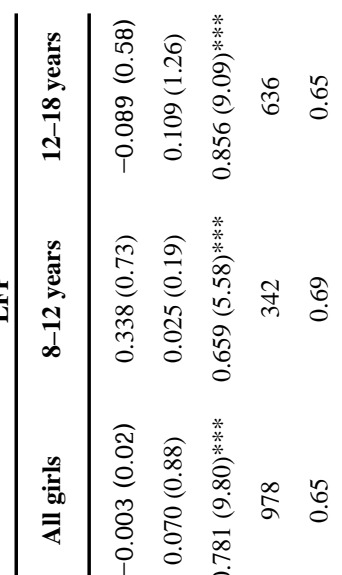


